\title{
THE EFFECTS OF FISCAL POLICY AT THE EFFECTIVE LOWER BOUND
}

\author{
Dennis Bonam \\ De Nederlandsche Bank, VU Amsterdam
}

JAKOB DE HAAN

De Nederlandsche Bank, University of Groningen and CESifo

\author{
Beau Soederhuizen \\ Netherlands Bureau for Economic Policy Analysis, Nyenrode Business \\ University
}

\begin{abstract}
We estimate the effects of government spending shocks during prolonged episodes of low interest rates, which we consider as proxy for the effective lower bound (ELB). Using a panel VAR model for 17 advanced countries, we find that both the government consumption and investment multipliers are significantly higher, and exceed unity, when interest rates are persistently low. Distinguishing between construction- and equipment-related government investments, we find that only the former raises output by significantly more when the ELB binds. This result can be explained by existing New Keynesian models featuring time-to-build constraints on government investment.
\end{abstract}

Keywords: Fiscal multipliers, Effective lower bound, Panel VAR

\section{INTRODUCTION}

Nowadays, many countries still struggle with the fallout of the global financial crisis, facing sluggish economic growth and inflation that is persistently (and sometimes far) below target. As monetary policy increasingly runs out of steam due to the effective lower bound (ELB) on the nominal interest rate and the decreasing effectiveness of unconventional policies [Blinder et al. (2017)], several policymakers have called upon fiscal policy to bring the economy back on track. For instance, the former vice-governor of the Federal Reserve stated: "Certain fiscal policies can increase the potential of the economy and help confront some of our longer-term economic challenges. By raising equilibrium interest rates, such policies may also reduce the probability that the economy, and the Federal

\footnotetext{
We would like to thank Pascal Jacquinot, Marien Ferdinandusse, and seminar participants at the Fiscal Policies Division of the European Central Bank, the Dutch Economist Day 2017, the Dutch Central Bank, and the IWEEE 2018, as well as three referees for their helpful comments and suggestions on a previous version of the paper. All errors are our own. The views expressed do not necessarily reflect the official position of De Nederlandsche Bank, the Eurosystem, or the CPB Netherlands Bureau of Policy Analysis. Address correspondence to: Dennis Bonam, De Nederlandsche Bank, Econometrics and Modeling Department, Westeinde 1, 1017 ZN, Amsterdam, The Netherlands. e-mail: d.a.r.bonam@dnb.nl
}

(C) 2020 Cambridge University Press. This is an Open Access article, distributed under the terms of the Creative Commons Attribution licence (http://creativecommons.org/licenses/by/4.0/), which permits unrestricted re-use, distribution, and reproduction in any medium, provided the original work is properly cited. $\quad 1469-8056 / 20149$ 
Reserve, will have to contend more than is necessary with the ELB on interest rates." [Fischer (2016)]. ${ }^{1}$ Likewise, in the letter of intent accompanying Juncker's 2016 State of the Union address, then-President of the European Commission announced his intention to promote "a positive fiscal stance for the euro area, in support of the monetary policy of the European Central Bank."

Several recent papers suggest that fiscal policy may be very effective when the economy is driven toward the ELB by fundamental shocks [e.g. Christiano et al. (2011), Eggertsson (2011) and Woodford (2011)]. Within a standard New Keynesian framework, increases in government spending raise aggregate demand and inflation (expectations) which, in the absence of monetary tightening, reduces the real interest rate and stimulates private spending, thereby raising aggregate demand and inflation further. To the extent that fiscal policy crowds in private spending through this "real interest rate" (or "expectations") channel, the government spending multiplier can exceed unity. However, some studies point out that the size of the multiplier also depends on the composition of the government spending shock. For example, Albertini et al. (2014), Drautzburg and Uhlig (2015), and Bouakez et al. (2017) show that the fiscal multiplier at the ELB following a shock in productive government spending, like public investment, can be less than one. This is because an increase in public investment reduces firms' real marginal costs, which lowers inflation expectations and raises the real interest rate, thereby depressing private spending and reducing the fiscal multiplier. ${ }^{2}$ Evidence in favor of this conjecture is provided by Boehm (2019) who finds, for a panel of OECD countries, much smaller government investment multipliers (of around 0) than government consumption multipliers (of around 0.8).

This paper provides new empirical evidence on the size of the fiscal multiplier at the ELB. Given the importance of the composition of the government spending shock in determining the size of the fiscal multiplier, we consider both government consumption and government investment shocks. Moreover, we further distinguish between construction- and equipment-related public investments. Since ELB spells are scarce, we consider prolonged episodes of low interest rates as a proxy for the ELB. In particular, to identify periods when the ELB is binding, we introduce an indicator which equals one when the short-term nominal interest rate is below $1 \%$ for 4 consecutive quarters, and zero otherwise. Further, we pool quarterly data for a sample of 17 advanced economies, covering the 1960Q12017Q4 period, and use a panel VAR model and short-run (Cholesky) restrictions to identify fiscal innovations and estimate government spending multipliers, in the spirit of Beetsma et al. (2008), Beetsma and Giuliodori (2011), and Ilzetzki et al. (2013).

We find that both the cumulative government consumption and investment multipliers are significantly higher, and exceed unity, when interest rates are persistently low. The government consumption multiplier peaks at around 2 at the ELB and 0.4 in normal times. For the government investment multiplier, the corresponding numbers are 1.2 and 0.8 . Moreover, we find the multiplier to be higher, the longer is the ELB spell or the lower is the threshold level for the 
interest rate below which the ELB is considered to be binding. We show that these results are consistent with the predictions of a conventional New Keynesian model. Furthermore, an increase in government investment raises the real interest rate in normal times, yet significantly lowers it at the ELB. This observation lends support to the real interest rate channel of fiscal policy. However, following a government consumption shock, the real interest rate drops significantly regardless of whether the ELB is binding or not. We perform robustness exercises that control for the prevailing exchange rate regime and the business cycle and perform tests to overcome potential anticipation (or "fiscal foresight") effects. We find that our main conclusions remain intact. ${ }^{3}$

Our finding of a larger government investment multiplier at the ELB casts doubt on the importance of negative supply-side effects of public investment. To investigate this issue more in depth, we distinguish between construction- and equipment-related government investment shocks. Bouakez et al. (2017) show that the longer it takes before public capital becomes productive, the more the deflationary effects of public investment are pushed into the future. ${ }^{4}$ We therefore expect that construction-related investment shocks have a stronger positive impact on inflation and output when the ELB is binding than equipment-related investment shocks, since the former are generally subject to more restrictive time-to-build constraints. Our results suggest that shocks in construction-related investment raise output by more when the economy is at the ELB than when it is not at the ELB, but the same does not hold for equipment-related investments. We also find that only construction-related investment shocks are able to lift inflation and reduce the real interest rate in times when the ELB binds, whereas equipmentrelated investment shocks are unable to do so. Therefore, our estimates of the effects of total public investment shocks seem to be driven by construction-related investments. As far as we know, we are the first to document the different effects of these different types of public investment at the ELB.

The remainder of the paper is structured as follows. Section 2 outlines how our paper is related to several strands of the literature. Section 3 provides a theoretical benchmark for the relationship between the fiscal multiplier and (the length of) ELB spells. This theoretical benchmark is meant to help interpret our empirical results. Section 4 describes the empirical strategy and the data used. Section 5 presents our estimation results and checks the robustness of our estimates. Finally, Section 6 concludes.

\section{RELATED LITERATURE}

Our work is related to a growing literature on fiscal multipliers at the ELB. ${ }^{5}$ For instance, using a New Keynesian model estimated for the USA, Cogan et al. (2010) do not find an amplifying effect of the ELB on the government spending multiplier, potentially because the bulk of the spending shock is assumed to occur outside the ELB spell. Ramey (2011) estimates a VAR model using quarterly US data and also finds no evidence of higher government spending multipliers at the 
ELB, identified as the period between 1939 and 1945. Moreover, Dupor and Li (2015) show that, during the US Federal Reserve's "passive" period of 19591979, inflation (expectations) did not respond strongly (or even negatively) to government spending shocks, thereby questioning the potency of the expectations channel of fiscal policy. However, using military news shocks and defining ELB spells as the 1932Q2-1951Q1 and 2008Q4-2015Q4 periods, Ramey and Zubairy (2018) do find higher cumulative fiscal multipliers at the ELB for the USA (reaching 1.4 after 2 years), but only when the rationing periods of WWII are excluded. For the UK, Crafts and Mills (2013) find that, during the low interest rate period of the 1930s, government spending multipliers range between 0.3 and 0.8 . The authors attribute these low estimates to a generally weak response of the real interest rate and high levels of government debt inherited from WWI. Evidence for Japan is more consistent. Morita (2015), for instance, uses a time-varying VAR model that imposes a nonnegativity constraint on the interest rate and finds that the effects of fiscal policy are stronger at the ELB due to a crowding-in effect on consumption. Similarly, Miyamoto et al. (2018) find higher multipliers (around 1.5) at the ELB, identified as the 1995Q4-2014Q1 period, than under normal circumstances (around 0.5), again due to a stronger response of consumption.

A number of recent studies applying panel VAR models also confirm higher fiscal multipliers when interest rates are low, such as Almunia et al. (2010), who focus on defense-spending shocks in 27 countries during the Great Depression, and the IMF (2017) study which obtains significantly larger fiscal spillover effects in 55 advanced and emerging market economies when either the recipient or source country is stuck at the ELB. Since we first circulated our paper in 2017, Klein and Winkler (2018) came up with a closely related paper in which they use data for a panel of 13 countries, adopting a similar approach as ours to identify ELB spells. Klein and Winkler (2018) find a higher government consumption multiplier when the ELB is binding, thereby confirming our results. A key difference with our paper is that they use military spending to identify exogenous government spending shocks. Furthermore, their paper does not address the role of the composition of the fiscal shock. The same holds for the papers cited above. We provide estimates for both the government consumption and investment multiplier and also show that whether the latter is higher at the ELB depends on what type of government investment is considered. ${ }^{6}$

Our paper is further related to theoretical studies on the interaction between fiscal policy and the ELB. ${ }^{7}$ Christiano et al. (2011), for instance, show that the government spending multiplier in a New Keynesian model exceeds unity when the ELB is binding and is larger the longer is the ELB spell, which is consistent with our empirical findings. Coenen et al. (2012) derive a similar result for both government consumption and investment multipliers. The multiplier can even be unbounded under a stochastic interest rate peg, as shown by Carlstrom et al. (2014). The size of the multiplier also hinges on the nature of the government spending shock. For instance, Woodford (2011) shows that the more persistent is the government spending shock, the more contractionary is the monetary 
policy response once the economy escapes the ELB and, through expectations, the weaker are the expansionary effects of fiscal policy at the ELB. Similarly, Erceg and Lindé (2014) show that the multiplier shrinks with the size of the government spending impulse, since a larger stimulus reduces the duration of the ELB spell.

Other papers fail to find fiscal multipliers that are higher when the economy is at the ELB than when it is not at the ELB. In Roulleau-Padeloup (2018), for example, an optimal monetary policy that successfully anchors inflation expectations prevents government spending shocks from sufficiently lifting inflation (expectations) at the ELB, thereby muting the size of the multiplier. Government spending shocks can even be deflationary when the ELB is caused by nonfundamental confidence shocks, as shown by Mertens and Ravn (2014) and Aruoba et al. (2018). Hills and Nakata (2008) show that the multiplier can be less than one at the ELB if the central bank's interest rate rule features a high degree of inertia, while in Kiley (2016), the multiplier is below one at the ELB if firms only slowly update their information. Fernández-Villaverde et al. (2015) and Boneva et al. (2016) argue that the size of the multiplier is also affected by the nonlinear features in the model caused by the ELB. These studies thus suggest that the role of the ELB in determining the size of the multiplier depends on the type of model considered.

\section{A THEORETICAL BENCHMARK}

Our empirical strategy involves the use of an indicator that splits the data sample into episodes when an economy is assumed to face the ELB and when it does not. Because (the robustness of) our empirical results necessarily hinge(s) on the definition of this indicator, we first provide a theoretical benchmark against which we can compare our results. In particular, we use a standard New Keynesian model to investigate how the presence of the ELB and the length of the ELB spell affect the transmission of fiscal shocks and the size of the fiscal multiplier.

In the first part of this section, we provide an overview of the model. In the second part, we use the model to illustrate the channels through which the ELB may amplify the effects of fiscal policy shocks. We also use the model to illustrate the role of time-to-build constraints on government investment.

\subsection{Model Description}

3.1.1. Household preferences. In each period $t$, a representative, infinitely-lived household chooses consumption, $c_{t}$, hours worked, $h_{t}$, holdings of nominal, oneperiod private bonds, $B_{t}$, and investment, $i_{t}$, in private capital, $k_{t}$, in order to maximize expected lifetime utility, which is given by

$$
E_{t} \sum_{t=0}^{\infty} \beta^{t} z_{D, t}\left(\frac{c_{t}^{1-\sigma}}{1-\sigma}-\frac{h_{t}^{1+\varphi}}{1+\varphi}\right)
$$


where $\beta \in(0,1)$ denotes the household's discount factor, $\sigma>0$ is the risk aversion coefficient, and $\varphi>0$ is the inverse Frisch elasticity of labor supply. The variable $z_{D, t}$ represents a preference shock whose dynamics are captured by a stationary $\mathrm{AR}(1)$ process. This preference shock is used to simulate an increase in the household's desire to save that takes the economy to the ELB. ${ }^{8}$

The household pays lump-sum taxes, $\tau_{t}$, to the government and receives labor income, $W_{t} h_{t}$ where $W_{t}$ denotes the nominal wage rate, and profits, $\mathcal{P}_{t}$, from firms which the household owns. Let $P_{t}$ be the aggregate price index, $r_{k, t}$ the real return on capital, and $R_{t}$ the gross nominal interest rate on private bonds. The household's budget constraint is then given by

$c_{t}+\frac{B_{t}}{P_{t}}+k_{t}-(1-\delta) k_{t-1}+\Gamma\left(i_{t}, k_{t-1}\right)+\tau_{t}=\frac{W_{t}}{P_{t}} h_{t}+\frac{R_{t-1}}{P_{t}} B_{t-1}+r_{k, t} k_{t-1}+\mathcal{P}_{t}$,

where $\delta \in[0,1]$ denotes the depreciation rate of private capital. The function $\Gamma(\cdot)$ governs the investment-adjustment costs and has the following form: ${ }^{9}$

$$
\Gamma\left(i_{t}, k_{t-1}\right)=\frac{\gamma}{2}\left(\frac{i_{t}}{k_{t-1}}-\delta\right)^{2} k_{t-1},
$$

with $\gamma \geq 0$. The household's first-order conditions have standard interpretations and are given by

$h_{t}^{\varphi}=c_{t}^{-\sigma} w_{t}$

$$
\begin{aligned}
1 & =\beta E_{t}\left[\frac{\lambda_{t+1}}{\lambda_{t}} \frac{R_{t}}{\pi_{t+1}}\right], \\
q_{t} & =1+\gamma\left(\frac{i_{t}}{k_{t-1}}-\delta\right), \\
q_{t} & =\beta E_{t}\left\{\frac{\lambda_{t+1}}{\lambda_{t}}\left[r_{k, t+1}+q_{t+1}(1-\delta)-\frac{\gamma}{2}\left(\frac{i_{t+1}}{k_{t}}-\delta\right)^{2}-\gamma\left(\frac{i_{t+1}}{k_{t}}-\delta\right) \frac{i_{t+1}}{k_{t}}\right]\right\}
\end{aligned}
$$

where $\pi_{t} \equiv P_{t} / P_{t-1}$ denotes gross inflation, $w_{t} \equiv W_{t} / P_{t}$ is the real wage rate, $\lambda_{t}$ is the marginal utility of consumption, and $q_{t}$ is Tobin's $\mathrm{Q}$.

3.1.2. Firms. Intermediate goods, $y_{t}(j)$, are produced by monopolistic firms, indexed by $j \in[0,1]$, using the following technology:

$$
y_{t}(j)=k_{t-1}(j)^{\alpha} h_{t}(j)^{1-\alpha} k_{g, t-1}^{\alpha_{g}},
$$

where $k_{g, t}$ denotes public capital and $\left\{\alpha, \alpha_{g}\right\} \in[0,1]$ measure the output elasticity with respect to private and public capital. Taking factor prices as given, the firm 
minimizes its costs which yields the following demand conditions for labor and private capital:

$$
w_{t}=(1-\alpha) \frac{y_{t}(j)}{h_{t}(j)} m c_{t}, \quad r_{k, t}=\alpha \frac{y_{t}(j)}{k_{t-1}(j)} m c_{t},
$$

where real marginal costs, $m c_{t}$, are denoted by

$$
m c_{t}=w_{t}^{1-\alpha} r_{k, t}^{\alpha} k_{g, t-1}^{-\alpha_{g}} \alpha^{-\alpha}(1-\alpha)^{\alpha-1} .
$$

Note that an increase in public capital leads to a reduction in real marginal costs.

Firms set prices with the aim of maximizing the discounted sum of current and future profits, conditional on the probability of non-price adjustment, which is governed by the parameter $\theta \in(0,1)$ [see Calvo (1983)]:

$$
E_{t} \sum_{k=0}^{\infty} \theta^{k} \mathcal{Q}_{t, t+k}\left(\bar{P}_{t} y_{t, t+k}(j)-W_{t+k} h_{t, t+k}(j)-P_{t+k} r_{k, t+k} k_{t, t+k-1}(j)\right),
$$

where $\bar{P}_{t}$ is the optimal price set by firm $j$ at $t$, and where $\mathcal{Q}_{t, t+k}=$ $\beta^{k} E_{t}\left[\left(\lambda_{t+k} / \lambda_{t}\right) \pi_{t+k}^{-1}\right]$ is the $k$-step ahead equilibrium pricing kernel. The pricesetting friction allows fiscal and monetary policy to have real (short-run) effects. Subject to (8), (9) and the firm-specific demand schedule

$$
y_{t}(j)=\left(\frac{P_{t}(j)}{P_{t}}\right)^{-\epsilon} y_{t},
$$

profit maximization leads to the following condition for the optimal price:

$$
\bar{P}_{t}=\frac{\epsilon}{\epsilon-1} \frac{E_{t} \sum_{k=0}^{\infty}(\theta \beta)^{k} P_{t+k}^{\epsilon} \lambda_{t+k} y_{t+k} m c_{t+k}}{E_{t} \sum_{k=0}^{\infty}(\theta \beta)^{k} P_{t+k}^{\epsilon-1} \lambda_{t+k} y_{t+k}},
$$

where $\epsilon>1$ measures the elasticity of substitution between intermediate goods. The aggregate price level is given by

$$
P_{t}=\left(\int_{0}^{1} P_{t}(j)^{1-\epsilon} d j\right)^{\frac{1}{1-\epsilon}} .
$$

3.1.3. Public sector. The government levies lump-sum taxes, $\tau_{t}$, to cover public expenditures, which consists of public consumption, $g_{t}^{c}$, and investment, $g_{t}^{i}: 10$

$$
\tau_{t}=g_{t}^{c}+g_{t}^{i}
$$

Public expenditures are exogenous and, for $x=\{c, i\}$, given by

$$
g_{t}^{x}=\rho_{g^{x}} g_{t-1}^{x}+\varepsilon_{g^{x}, t}
$$

with $\rho_{g} x \in[0,1]$. Public capital evolves according to

$$
k_{g, t}=\left(1-\delta_{g}\right) k_{g, t-1}+g_{t}^{i}
$$


with $\delta_{g} \in[0,1]$. In the analysis below, we focus on shocks to government consumption and investment, that is, $\varepsilon_{g^{x}, t}$, which are assumed to be normally distributed with zero mean and variance $\sigma_{g^{x}}^{2}$.

Monetary policy is described by the following interest rate feedback rule:

$$
R_{t}=\max \left(1, Z_{t}\right) \text {, }
$$

where

$$
\frac{Z_{t}}{Z}=\left(\frac{\pi_{t}}{\pi}\right)^{\phi_{\pi}}\left(\frac{y_{t}}{y}\right)^{\phi_{y}}, \quad \phi_{\pi}>1, \quad \phi_{y} \geq 0 .
$$

Due to the occasionally binding constraint implied by (17), we use the OccBin toolkit of Guerrieri and Iacoviello (2015) to solve the (linearized version of the) model. ${ }^{11}$

3.1.4. Market clearing. Aggregate output is defined as

$$
y_{t}=\left(\int_{0}^{1} y_{t}(j)^{\frac{\epsilon-1}{\epsilon}} d j\right)^{\frac{\epsilon}{\epsilon-1}} .
$$

Using appropriate aggregators for labor and capital, the following goods and labor market clearing conditions can be derived:

$$
\begin{aligned}
& y_{t}=c_{t}+i_{t}+g_{t}^{c}+g_{t}^{i}, \\
& y_{t}=k_{t-1}^{\alpha} h_{t}^{1-\alpha} k_{g, t-1}^{\alpha_{g}} d_{t}^{-1},
\end{aligned}
$$

where $d_{t} \equiv \int_{0}^{1}\left(P_{t}(j) / P_{t}\right)^{-\epsilon} d j$ is a measure of price dispersion.

3.1.5. Calibration. The parameters are calibrated based on a quarterly frequency of $t$. For most parameters, we use values that are commonly used in the literature. Table 1 provides an overview of the benchmark calibration.

With regard to the output elasticity to public capital, governed by $\alpha_{g}$, the literature offers little guidance due to a lack of consensus on the effects of public capital on productivity [see Baxter and King (1993) and Leeper et al. (2010), for a discussion]. Here, we use $\alpha_{g}=0.08$ as a benchmark, which lies in between the values considered by Leeper et al. (2010). Choices for the steady-state values, which are based on long-run averages for OECD countries, imply a steady-state government investment to output ratio, $g^{i} / y$, of $5 \%$, which is the same number used by Baxter and King (1993).

\subsection{The Effects of Fiscal Shocks at the Effective Lower Bound}

We plot the impulse response functions of selected variables to a government spending shock when the ELB is not binding and when it is binding. In the former case, we compare a baseline scenario without shocks to an alternative scenario in which a transient government spending shock occurs in the sixth period. In the latter case, the baseline scenario includes a preference shock that pushes 
TABLE 1. Benchmark calibration

\begin{tabular}{lll}
\hline Parameter & \multicolumn{1}{c}{ Description } & Value \\
\hline$\sigma$ & Risk aversion coefficient & 1.5 \\
$\varphi$ & Inverse Frisch elasticity of labor supply & 2 \\
$\beta$ & Household discount factor & 0.99 \\
$\gamma$ & Investment-adjustment cost parameter & 6 \\
$\delta, \delta_{g}$ & Depreciation rate of capital & 0.02 \\
$\alpha$ & Output elasticity w.r.t. private capital & 0.33 \\
$\alpha_{g}$ & Output elasticity w.r.t. public capital & 0.08 \\
$\theta$ & Probability of non-price adjustment & 0.75 \\
$\rho_{D}, \rho_{g^{x}}$ & AR(1) coefficient of demand and fiscal shocks & 0.9 \\
$\phi_{\pi}$ & Monetary policy response to inflation & 1.5 \\
$\phi_{y}$ & Monetary policy response to output & 0.25 \\
$g^{c} / y$ & Steady-state public consumption ratio & 0.2 \\
$c / y$ & Steady-state private consumption ratio & 0.6 \\
$i / y$ & Steady-state private investment ratio & 0.15 \\
\hline
\end{tabular}
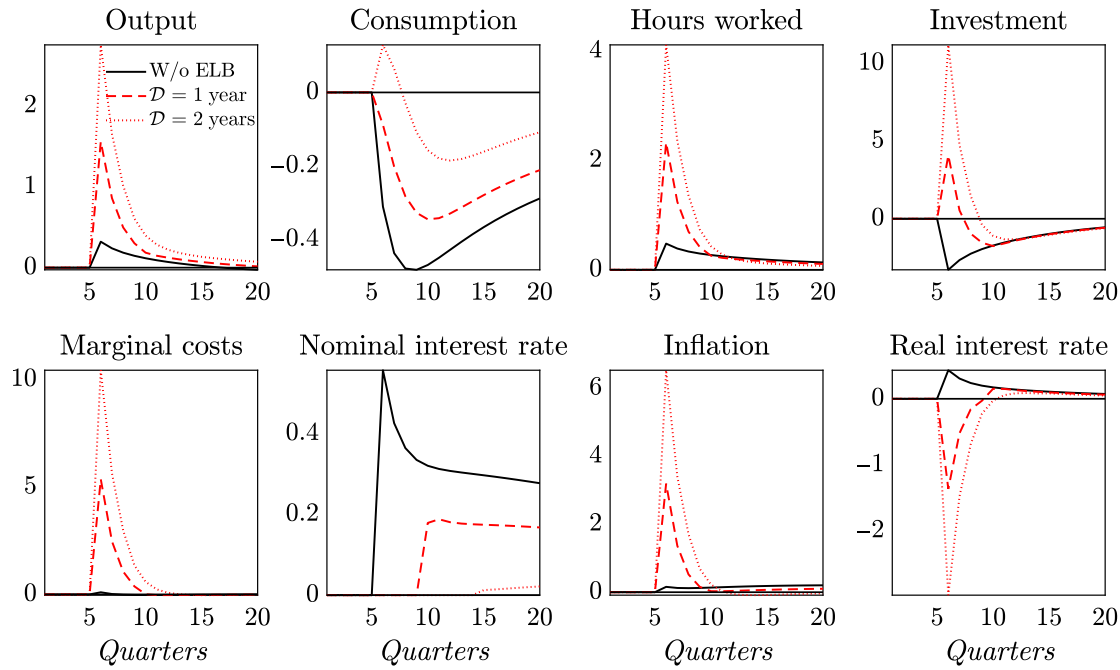

Notes: The government consumption shock is scaled to be $1 \%$ of steady-state output. The impulse response functions show deviations from the baseline scenario without fiscal shocks (in percentage points). The nominal and real interest rate and inflation are annualized percentages. $\mathcal{D}$ denotes the duration of the ELB spell.

FIGURE 1. Impulse responses to a government consumption shock.

the economy toward the ELB, while the alternative scenario includes both this preference shock and the fiscal shock.

Figure 1 shows the responses to a government consumption shock. The theoretical model predicts an increase in output following a rise in government 
consumption. When the ELB is binding, the output response is larger and the impact multiplier (i.e. the output response in the period when the fiscal shock occurs) exceeds unity. ${ }^{12}$ The differences in output responses between nonbinding and binding ELB episodes is more pronounced, the longer the duration of the ELB spell.

Due to an increase in aggregate demand, labor demand goes up which raises real wages, marginal costs, and hours worked. Moreover, labor supply rises due to a negative wealth effect on consumption: as households anticipate higher future taxes (required to finance the current fiscal expansion), they are willing to work more to smooth lifetime consumption. This negative wealth effect also causes consumption to fall in response to the fiscal shock. However, when the ELB is binding, consumption falls by less and can even respond positively to the government consumption shock if the duration of the ELB spell is sufficiently long. The possibility of a positive consumption response arises from a rise in inflation (which is due to the rise in marginal costs) which, given a temporarily fixed nominal interest rate, lowers the real interest rate. This real interest rate effect on consumption counteracts the negative wealth effect, which thereby enhances the government consumption multiplier and allows it to exceed unity. The response of private investment to the government consumption shock can be explained by the real interest rate effect as well. When the ELB is not binding, investment falls due to the rise in the policy rate and the negative wealth effect. In contrast, when the ELB is binding, investment rises as the increase in aggregate demand raises the net return on capital. Thus, the presence of a binding ELB reduces the crowding-out effect of fiscal policy on private spending and raises the government consumption multiplier.

Figure 2 shows the responses to a government investment shock. Again, the government investment multiplier is higher when the ELB is binding than when it is not. The channel through which the ELB amplifies the effects of the government investment shock is similar to the one corresponding to a government consumption shock. Eggertsson (2011), however, cautions for the use of supplyside policies when an economy faces the ELB. On the one hand, an increase in public investment immediately raises aggregate demand, which raises real marginal costs and inflation, and thereby lowers the real interest rate. On the other hand, since government investment reduces firms' real marginal costs, as shown by equation (10), it tends to reduce inflation (expectations), and thereby raises the real interest rate. These counteracting demand- and supply-side effects both determine the overall response of output to the government investment shock. Which of these two effects dominates depends, among other things, on the duration of the ELB spell, $\mathcal{D}$. In fact, Figure 2 shows that extending the ELB spell from 1 to 2 years still raises the government investment multiplier, yet by less. This suggests that the longer ELB spell also strengthens the supply-side effect. When the ELB spell is sufficiently long, a government investment shock can even yield a negative output response (not shown). 

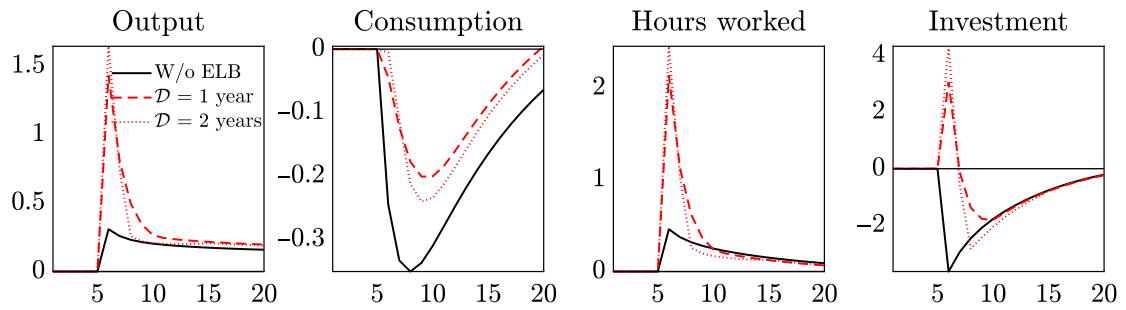

Marginal costs
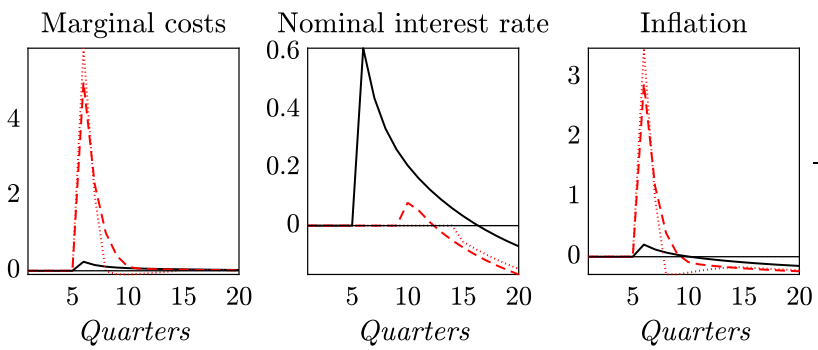

Real interest rate

Notes: The government investment shock is scaled to be $1 \%$ of steady-state output. The impulse response functions show deviations from the baseline scenario without fiscal shocks (in percentage points). The nominal and real interest rate and inflation are annualized percentages. $\mathcal{D}$ denotes the duration of the ELB spell.

FIGURE 2. Impulse responses to a government investment shock.
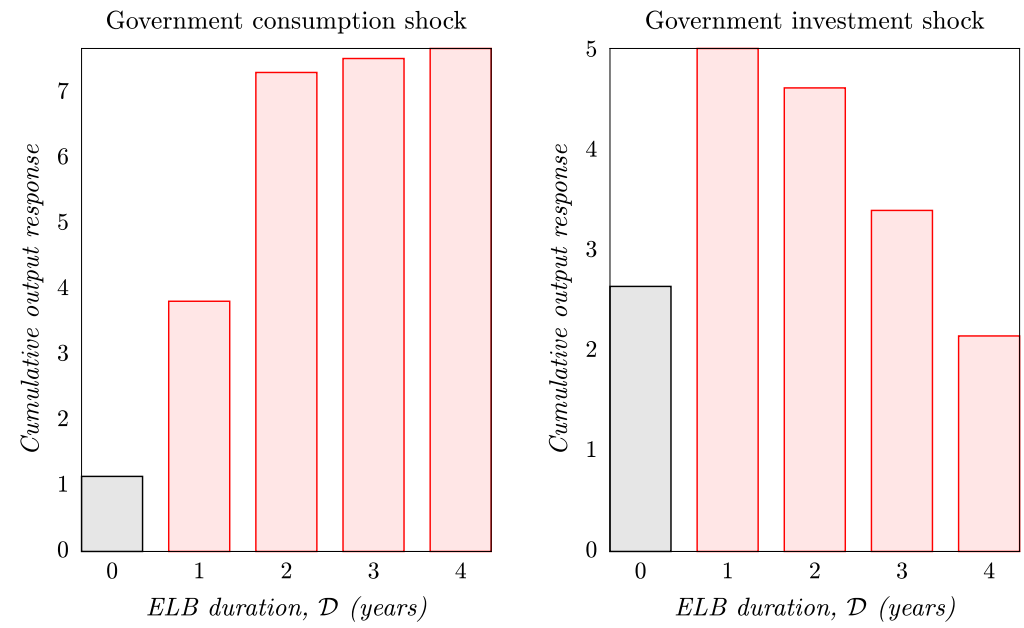

FIGURE 3. Cumulative fiscal multipliers and the role of the ELB duration, $\mathcal{D}$.

In Figure 3, we further investigate the role of the duration of the ELB spell, which we denote by $\mathcal{D}$, and plot the cumulative fiscal multiplier as a function of $\mathcal{D}$. When $\mathcal{D}=0$, the ELB is not binding. The cumulative fiscal multiplier is calculated as the discounted sum of the output responses over 20 quarters. As 
Government investment shock
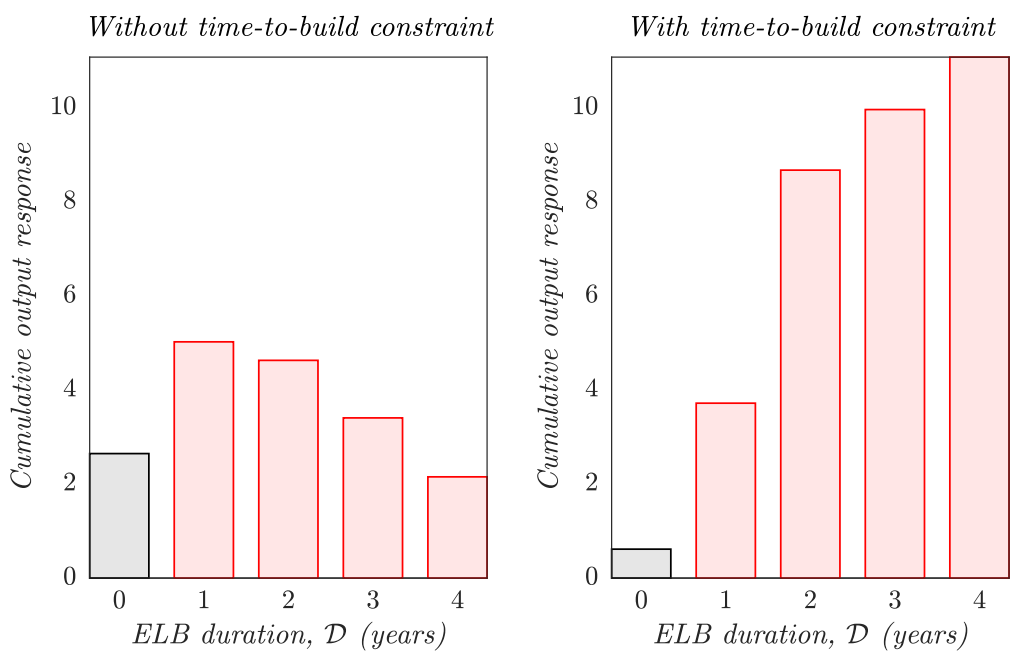

Notes: Under the time-to-build constraint, we assume that it takes 4 years before public investment becomes productive.

FiguRE 4. Cumulative fiscal multipliers without and with a time-to-build constraint on government investment.

the figure shows, increasing the duration of the ELB spell raises the cumulative government consumption multiplier (left-hand side panel). Intuitively, the longer it takes before the economy escapes the ELB, the stronger is the real interest rate effect and thus the smaller are the crowding-out effects of fiscal policy. On the other hand, the marginal effect of $\mathcal{D}$ on the cumulative government investment multiplier turns negative once $\mathcal{D}$ exceeds a certain threshold. Therefore, these numerical results indicate that the negative supply-side effects, as discussed by Eggertsson (2011), start to bite once an economy is stuck in a liquidity trap for a long time.

When the supply-side effects of government investment shocks are pushed into the future due to time-to-build constraints, the positive demand-side effects may dominate, even when the ELB spell is highly persistent. Bouakez et al. (2017) illustrate this result using a New Keynesian model featuring time-to-build constraints on government investment. Here, we take a similar approach and change the model slightly by assuming that it takes 4 years before government investments become productive. The right-hand side panel of Figure 4 shows that, in the presence of this time-to-build constraint, extending the ELB spell now also monotonically raises the cumulative government investment multiplier.

The results from Figures 3 and 4 on the role of the ELB duration and the timeto-build constraint on government investment serve as a theoretical benchmark to interpret our empirical findings. 


\section{EMPIRICAL STRATEGY}

\subsection{A Proxy for the Effective Lower Bound}

Although interest rates set by central banks have been historically low in recent years, prolonged spells at the ELB are scarce. With the Bank of Japan being a notable exception, none of the world's major central banks were confronted with the ELB during the five decades preceding the Great Recession of 2008.

Therefore, in order to assess the effects of fiscal policy at the ELB, we need to define a suitable proxy for the ELB. We consider an economy as being bound by the ELB when the nominal interest rate has been below 1\% during the last 4 consecutive quarters. Hence, letting $R_{n, t}$ denote the nominal interest rate set by the central bank at quarter $t$ in country $n$, the indicator $\mathcal{I}_{n, t}$ used in our analysis to identify ELB episodes is determined as follows:

$$
\mathcal{I}_{n, t}= \begin{cases}1 & \text { if }\left\{R_{n, t-s} \mid s=0,1,2,3\right\}<1 \%, \\ 0 & \text { otherwise }\end{cases}
$$

We use this indicator to split our sample into two subsamples: one with and one without prolonged episodes of low interest rates. ${ }^{13,14}$ As a robustness check, we experiment with alternative proxies for the ELB by altering both the threshold for the interest rate and the number of consecutive quarters during which the interest rate must be below this threshold, that is, the ELB duration. This robustness exercise is important, because our baseline value for the ELB threshold of $1 \%$ is only a proxy for the level at which the nominal interest rate is bound by the ELB (which may differ across countries). Further, altering the ELB duration allows us to verify whether our results match with those of the theoretical benchmark discussed earlier. ${ }^{15}$

The top panel of Figure 5 shows the evolution of the nominal policy interest rate, for the group of advanced economies that we consider in the empirical analysis below, between 1993Q2 and 2017Q4 (during which data for all countries are available). The red horizontal dashed line shows the threshold value for the interest rate that is used in the definition of the ELB proxy. The figure illustrates the sharp monetary response to the 2008 crisis in most of the countries in the sample. The bottom panel shows the fraction of time each country spent at the ELB during this period, according to our proxy formalized by (21). The Japanese economy faced the ELB throughout almost all years between 1993 and 2017. The euro area countries spent the same number of quarters at the ELB, starting in 2012Q3, reflecting that these countries have a common monetary policy. ${ }^{16}$ For the USA and the UK, one ELB spell is identified which started around 2009. Over the whole sample considered, we identify a total of 373 ELB incidences. 
(a)

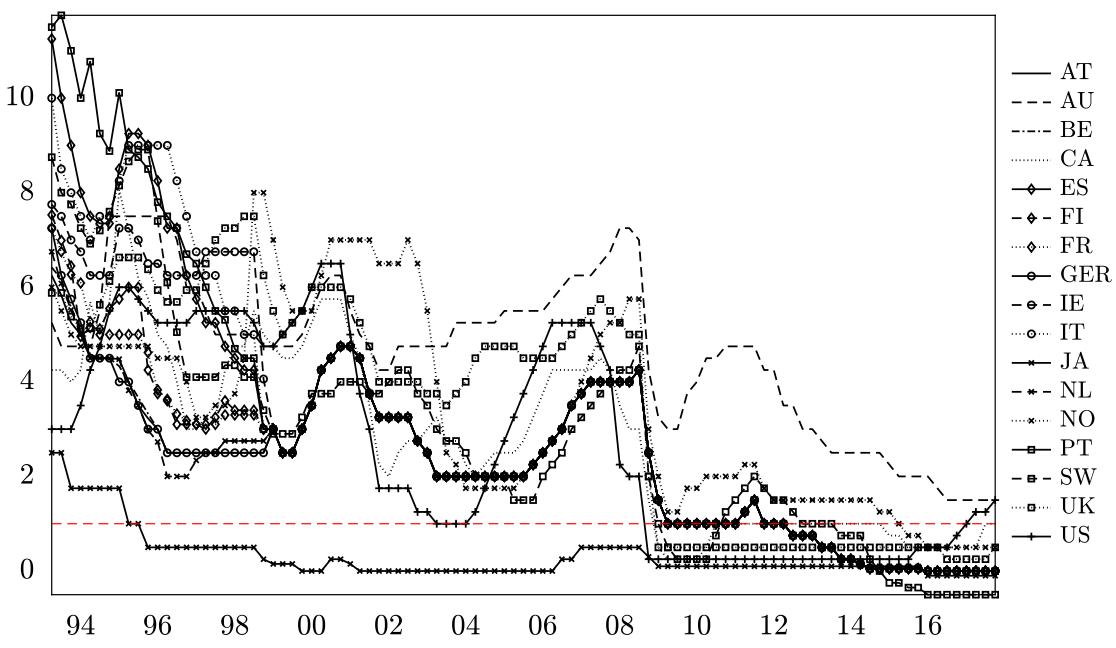

(b)

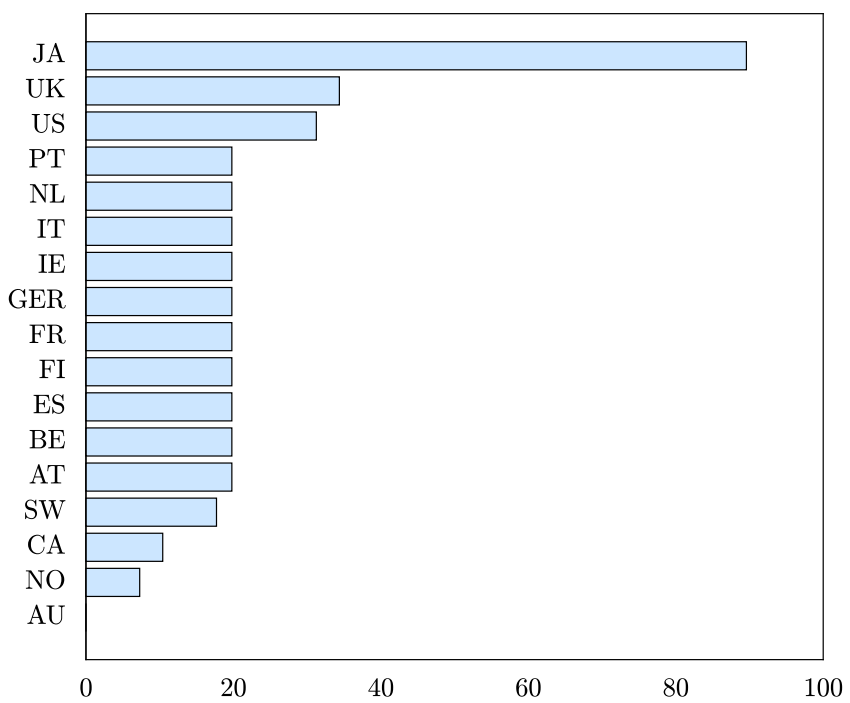

Notes: Countries are assumed to face the ELB when the nominal interest rate has been below $1 \%$ for the last 4 consecutive quarters, see equation (21). Source: Datastream, OECD Quarterly National Accounts Database and own calculations.

FiguRE 5. Nominal interest rates and ELB incidences. (a) Nominal interest rates (\%). (b) Fraction of time spent in ELB spells (\%), 1993Q2-2017Q4 


\subsection{A Panel VAR Model}

Estimating fiscal multipliers, defined as the percentage change in aggregate output due to a $1 \%$ change in government spending (as a share of output), is made difficult due to problems of endogeneity. The dynamics of fiscal variables are, typically, not determined by exogenous stochastic processes, yet depend on the, potentially country-specific and time-varying, institutional framework that defines how fiscal policy responds to changes in economic conditions and vice versa. Throughout the years, various methods have been proposed to isolate these endogenous responses of fiscal policy [see, e.g. Perotti (2008), Hall (2009), and Hebous (2011), for overviews]. Of these methods, the Vector Autoregression (VAR) model has become the most popular and frequently used method to estimate the effects of fiscal policy shocks [Stock and Watson (2001), Perotti (2008), and Ilzetzki et al. (2013)].

The VAR model is a system of linear equations in which the dependent variables are a function of their own lags and those of the other dependent variables. The parameters governing the dynamics of this system can be estimated by OLS, along with the variance-covariance matrix of the residuals, $\Sigma$. Since these residuals may be correlated with each other, certain identifying restrictions on $\Sigma$ need to be imposed in order to recover the structural shocks from the estimated residuals. Here, we follow the commonly used short-run restriction in which $\Sigma$ is transformed to a lower-triangular matrix through application of the Cholesky decomposition [see Blanchard and Perotti (2002)]. ${ }^{17}$ Once transformed this way, the variable ordered first in the VAR responds to its own shocks contemporaneously and to changes in the other variables with a lag. The second variable responds contemporaneously to the first variable and its own shock, the third variable to the first two variables and its own shock, and so on. This decomposition therefore implies that the variable ordered first can be considered 'exogenous'.

One of the problems of VAR models is that they can become quickly overparameterized, especially if the number of variables and lags included in the VAR are large. Having many parameters to estimate reduces the degrees of freedom and thereby the likelihood of obtaining significant estimates. This can be particularly problematic in our case, since we split the sample into periods in which the ELB is binding and when it is not, which reduces the number of observations. In order to maintain a sufficiently large sample size, we follow Beetsma et al. (2008), Beetsma and Giuliodori (2011), and Ilzetzki et al. (2013), among others, and pool data of a panel of 17 advanced economies. In addition, we keep the size of the VAR model limited by including only four variables: real government consumption, $g_{n, t}^{c}$, real aggregate output, $y_{n, t}$, inflation, $\pi_{n, t}$, and the real interest rate, $r_{n, t}$. The inclusion of inflation and the real interest rate helps identify the channels through which fiscal shocks are transmitted to the economy. ${ }^{18}$

Having the variables ordered such that $g_{n, t}^{c}$ enters the model first, $y_{n, t}$ second, $\pi_{n, t}$ third and $r_{n, t}$ last, we implicitly assume government consumption to be unaffected contemporaneously in period $t$ by any of the other variables. The intuition here follows from Blanchard and Perotti (2002) who argue that fiscal policy, when 
responding to economic conditions, is often hampered by decision lags as fiscal policy measures need to be approved by parliament and might be encumbered by implementation lags as well. Since we are using quarterly data, the assumption that governments do not respond to economic conditions within the same quarter is reasonable. The ordering of the remaining endogenous variables is consistent with standard New Keynesian models in which output affects inflation immediately through changes in real marginal costs and where the interest rate adjusts after changes in output and inflation are observed. Since we are only interested in identifying the government spending shock, alternative orderings would yield identical results, as long as government spending remains ordered first [see Christiano et al. (1999)]. ${ }^{19}$

The panel VAR model, which we estimate separately for each sample in which the ELB is either binding or not, is given by

$$
A Y_{n, t}=\sum_{k=1}^{K} B_{k} Y_{n, t-k}+C \varepsilon_{n, t},
$$

with $Y_{n, t}=\left[g_{n, t}^{c} y_{n, t} \pi_{n, t} r_{n, t}\right]^{\prime}$. The coefficient matrices $B_{k}$ govern the dynamic responses to the $k^{\text {th }}$ lags of the endogenous variables. The matrix $A$ describes the contemporaneous, and therefore endogenous, relationships between government consumption, output, inflation, and the real interest rate. The matrix $C$ is diagonal, which implies that the structural shocks, $\varepsilon_{n, t}$, are uncorrelated. To recover these shocks, equation (22) is estimated in reduced form, that is,

$$
Y_{n, t}=A^{-1} \sum_{k=1}^{K} B_{k} Y_{n, t-k}+e_{n, t},
$$

where $e_{n, t}$ now denotes a vector containing the reduced-form shocks. In order to find the relationship between $e_{n, t}$ and $\varepsilon_{n, t}$, that is, $\varepsilon_{n, t}=C^{-1} A e_{n, t}$, we apply the Cholesky decomposition on the variance-covariance matrix of $e_{n, t} \cdot{ }^{20}$ Following Ilzetzki et al. (2013), we control for cross-country heterogeneity by demeaning the data, which is equivalent to controlling for country-specific intercepts. The lag structure is determined by Akaike's Information Criterion (AIC). This criterion suggests an optimal lag length of $K=5$, regardless of whether we consider the sample with persistently low interest rates or not. Given that the data are quarterly, including five lags seems sufficient to capture the dynamic relationships of the endogenous variables. ${ }^{21}$

At this point, a word of caution is appropriate, since VAR-based impulse response functions may suffer from a projection bias as they are complex nonlinear functions of a constant set of estimated coefficients. For this reason, Jordà (2005) suggests to apply the Local Projection (LP) method, in which impulse response functions are generated using a new set of coefficients for each forecast horizon. ${ }^{22}$ As a check on whether our results are plagued by the projection bias, we also apply the LP method to obtain the responses to government expenditure 
shocks, using the shocks obtained from our panel VAR model. The results from this robustness exercise are reported in the Appendix to the paper and are qualitatively similar to our baseline results.

Another potential bias may arise when agents anticipate fiscal impulses before the actual shock materializes. In order to account for these "anticipation effects," we extend the baseline model by including the 10-year sovereign bond yield. The idea is that this "forward-looking variable" captures expectations about the future path of fiscal variables. We turn to these (and other) robustness exercises in Section 5.

\subsection{Data Description}

To estimate equation (23), we use quarterly data, covering 1960Q1-2017Q4, for 17 countries: Australia, Austria, Belgium, Canada, Finland, France, Germany, Ireland, Italy, Japan, Netherlands, Norway, Portugal, Spain, Sweden, the UK, and the USA. For some countries, the sample period is shorter, most notably for Canada, Finland, and Norway for which data are available only after the early 1990s. As mentioned earlier, the advantage of using quarterly rather than annual data is that it makes our identifying assumption of a zero-within quarter fiscal response to output more plausible. Another advantage over annual data is that quarterly data offer more observations.

For aggregate output, $y_{n, t}$, we use data on gross domestic product (GDP) in real terms, based on chained-volume estimates. For government consumption (investment), $g_{n, t}^{c}\left(g_{n, t}^{i}\right)$, data on general government final consumption (investment) expenditure is used. Both series are adjusted for seasonal effects. We then transform the series into real terms using the GDP deflator, take logs, demean the data (to control for country-fixed effects), and, finally, take a quadratic trend. Inflation, $\pi_{n, t}$, is calculated as the year-on-year percentage change in the consumer price index (all items). The real interest rate, $r_{n, t}$, is calculated as the difference between the nominal policy interest rate and the inflation rate in the subsequent period, that is, $r_{n, t}=R_{n, t}-\pi_{n, t+1} \cdot{ }^{23}$ All data are retrieved from Datastream and (for missing observations) the OECD Quarterly National Accounts dataset.

\section{ESTIMATION RESULTS}

\subsection{The Effects of Government Consumption}

In this section, we present the responses of our variables of interest, that is, $x_{t}=$ $\left\{g_{t}^{c}, y_{t}, \pi_{t}, r_{t}\right\}$, to a government consumption shock. In what follows, we transform these responses by taking the discounted sum and dividing through by the discounted cumulative response of government consumption, $g_{t}^{c}$. As such, the responses shown can be referred to as "cumulative multipliers" [see Uhlig (2010)]:

$$
\text { cumulative multiplier }(T)=\frac{\sum_{t=0}^{T}(1+s r)^{-t} \Delta x_{t}}{\sum_{t=0}^{T}(1+s r)^{-t} \Delta g_{t}^{c}},
$$




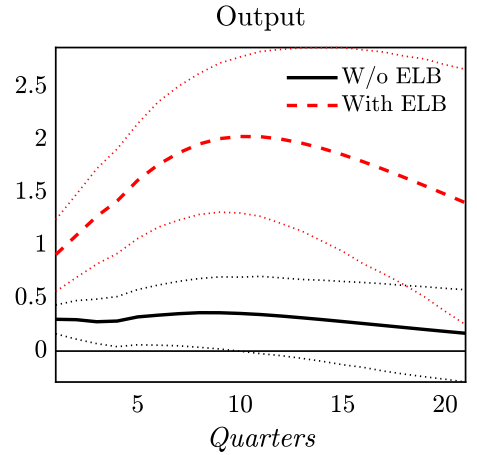

Real interest rate

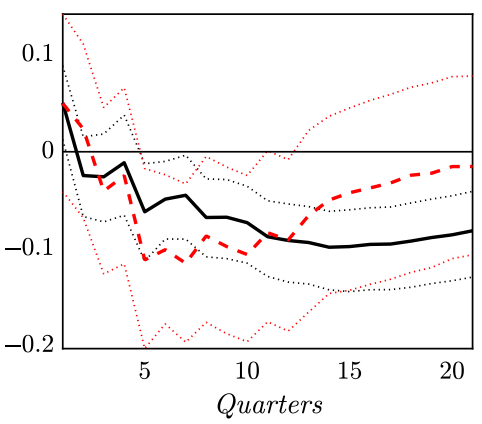

Inflation

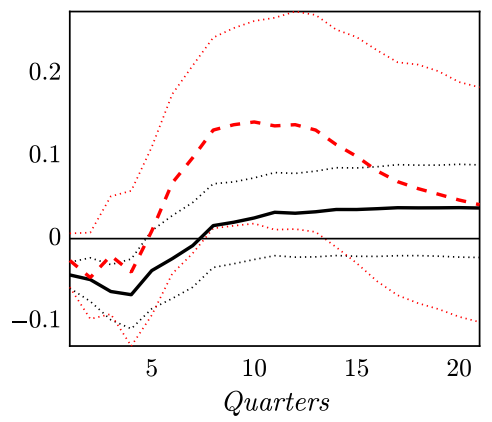

Government consumption

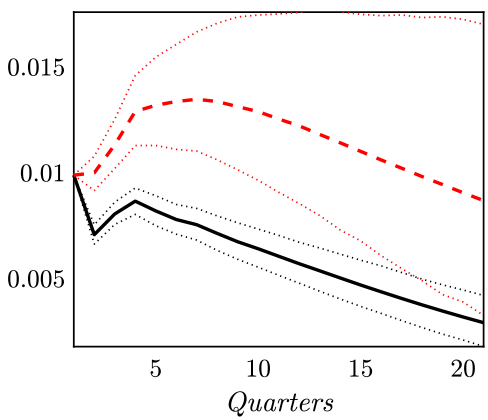

Notes: The shock is scaled to be $1 \%$ of GDP. The dotted lines show the $90 \%$ confidence interval. Units are in percentages for output and government spending and in percentage points for inflation and the real interest rate.

FIGURE 6. Cumulative multipliers following a government consumption shock.

where $T$ is the impulse response horizon and $s r$ is the median short-term interbank offered rate in the sample. When the variable of interest is GDP, we also use the term "cumulative fiscal multiplier." Further, we scale the cumulative multiplier by the average ratio between government consumption and GDP, such that the size of the shock is measured as a percentage of GDP. Inference is based on bootstrapping using Monte Carlo simulations and 1000 draws.

Figure 6 shows the results. The figure suggests that the response of GDP to the government consumption shock is positive and significant, no matter whether the ELB is binding or not. As discussed in Section 3, the positive response of GDP reflects that an increase in aggregate demand, provoked by the fiscal expansion, drives up production and expected marginal costs, and leads to an increase in inflation (the VAR model shows that this occurs with a lag). Consequently, the real interest rate falls, which raises aggregate demand and production further, and also raises private spending. Surprisingly, the response of the real interest rate is negative also in times when the ELB is not binding, which is different from what we would expect based on the New Keynesian model presented in Section 3. 
Figure 6 further reveals that, when the economy is not at the ELB, the fiscal multiplier is well below unity on impact, around 0.3. In the quarters that follow, the cumulative fiscal multiplier slowly declines and is no longer significantly different from zero after 2 years, reflecting that fiscal policy only has short-run effects on the real economy [Fatás and Mihov (2001), Blanchard and Perotti (2002), and De Castro and de Cos (2008)]. ${ }^{24}$ The results are quite different when the economy faces the ELB. In fact, the response of GDP to the government consumption shock is significantly stronger when the economy is at the ELB than in the absence of the ELB. After about 2 years following the shock, the cumulative fiscal multiplier peaks at around 2, compared to a peak of only 0.4 in the baseline scenario. The difference between these maximum cumulative fiscal multipliers is statistically significant. ${ }^{25,26}$

Hence, although the results shown in Figure 6 confirm the conclusions of existing theoretical contributions [Christiano et al. (2011), Eggertsson (2011), and Woodford (2011)], that is, the government consumption multiplier is larger at the ELB than in normal times, they may not be driven by the real interest rate channel as we do not find a statistically significant difference in the responses of the real interest rate to the government consumption shock across the two states. Nevertheless, the point estimates do show a stronger positive response of inflation and a stronger negative response of the real interest rate when the ELB is binding.

\subsection{The Effects of Government Investment}

We now investigate the responses to a government investment shock (of $1 \%$ of GDP). Following Ilzetzki et al. (2013), we add government investment, $g_{n, t}^{i}$, to the VAR model (23) and assume $g_{n, t}^{i}$ enters before the other variables, such that $Y_{n, t}=\left[g_{n, t}^{i} g_{n, t}^{c} y_{n, t} \pi_{n, t} r_{n, t}\right]^{\prime} .^{27}$ For this model, the AIC suggests an optimal lag length of six quarters for the sample without the ELB and eight quarters for the sample with the ELB. In order to make the two samples comparable, we set the lag length equal to $K=6$ for both samples. The results for the two different lag structures are, however, very similar.

As shown in Figure 7, government investment raises GDP, both when nominal interest rates are at their ELB and when they are not, but the response of GDP is significantly more pronounced under the ELB. We find a maximum cumulative fiscal multiplier of 1.2 if the economy is at the ELB, compared to a peak of 0.8 when it is not. In contrast to the previous results for government consumption shocks, the real interest rate channel now does seem to be important, given that we observe a positive real interest rate response in normal times, yet a significant decline of the real interest rate at the ELB. ${ }^{28}$

As discussed in Section 3, an increase in public investment reduces firms' marginal costs (ceteris paribus), thereby reducing inflation (expectations). If the central bank is constrained by the ELB and keeps the nominal interest rate fixed, this could lead to an increase in the real interest rate which suppresses the response of consumption and output to the public investment shock. The fact 

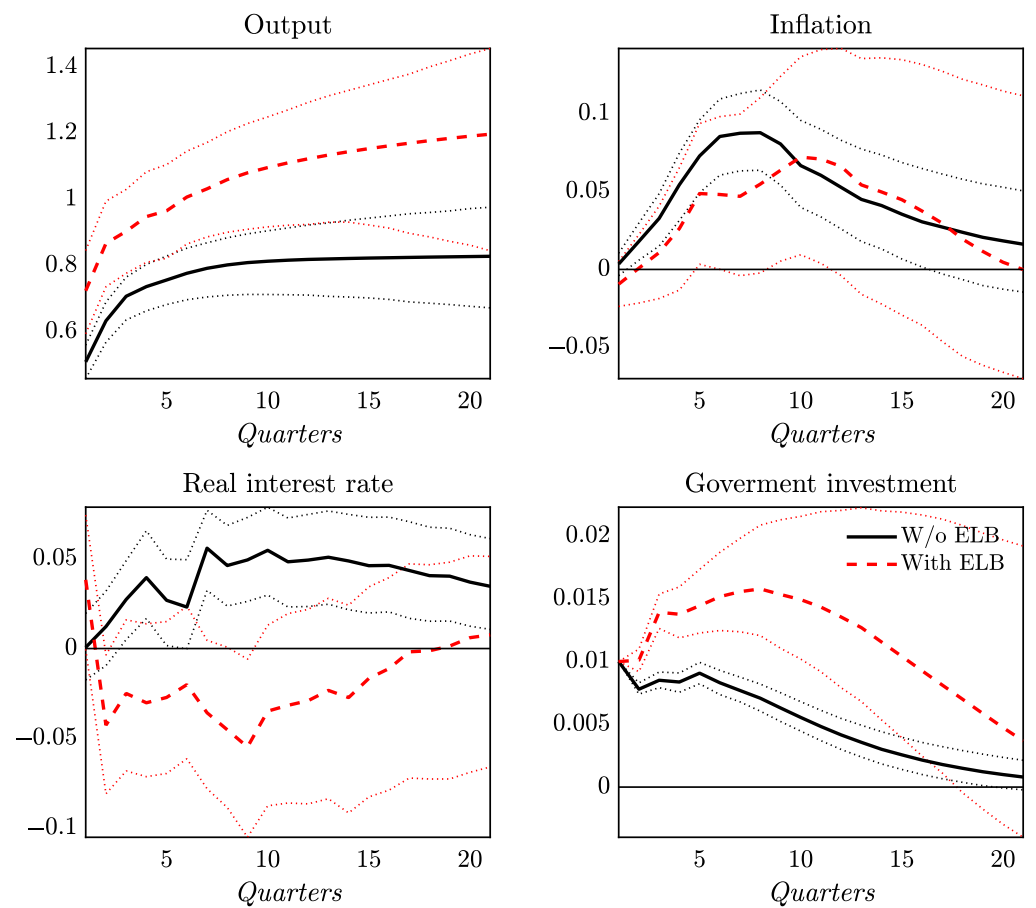

Notes: The shock is scaled to be $1 \%$ of GDP. The dotted lines reflect the $90 \%$ confidence interval. Units are in percentages for output and government spending and in percentage points for inflation and the real interest rate.

FIGURE 7. Cumulative multipliers following a government investment shock.

that we find a higher public investment multiplier at the ELB than in normal times implies that this negative supply-side effect of public investment is too weak to dominate the positive demand-side effect. This is consistent with the results from our theoretical model, where shocks to government investment yield higher output responses at the ELB, as long as the ELB spell is sufficiently short. However, as in our theoretical model, some signs of the negative supply-side effect of public investment can be inferred from the cumulative multipliers shown in Figure 7. In particular, the inflation response to the public investment shock is lower at the ELB than in normal times, whereas the reverse holds for the government consumption shock. This more muted response of inflation at the ELB also translates into a less pronounced decline in the real interest rate following the public investment shock than following the government consumption shock.

The negative supply-side effects of public investment become even more visible when we distinguish between public investment related to construction and to equipment. The former is likely to be subject to more restrictive time-to-build constraints than the latter. We modify the VAR model by replacing $g_{n, t}^{i}$ by either its construction- or equipment-related subcomponents. In both cases, we change the 

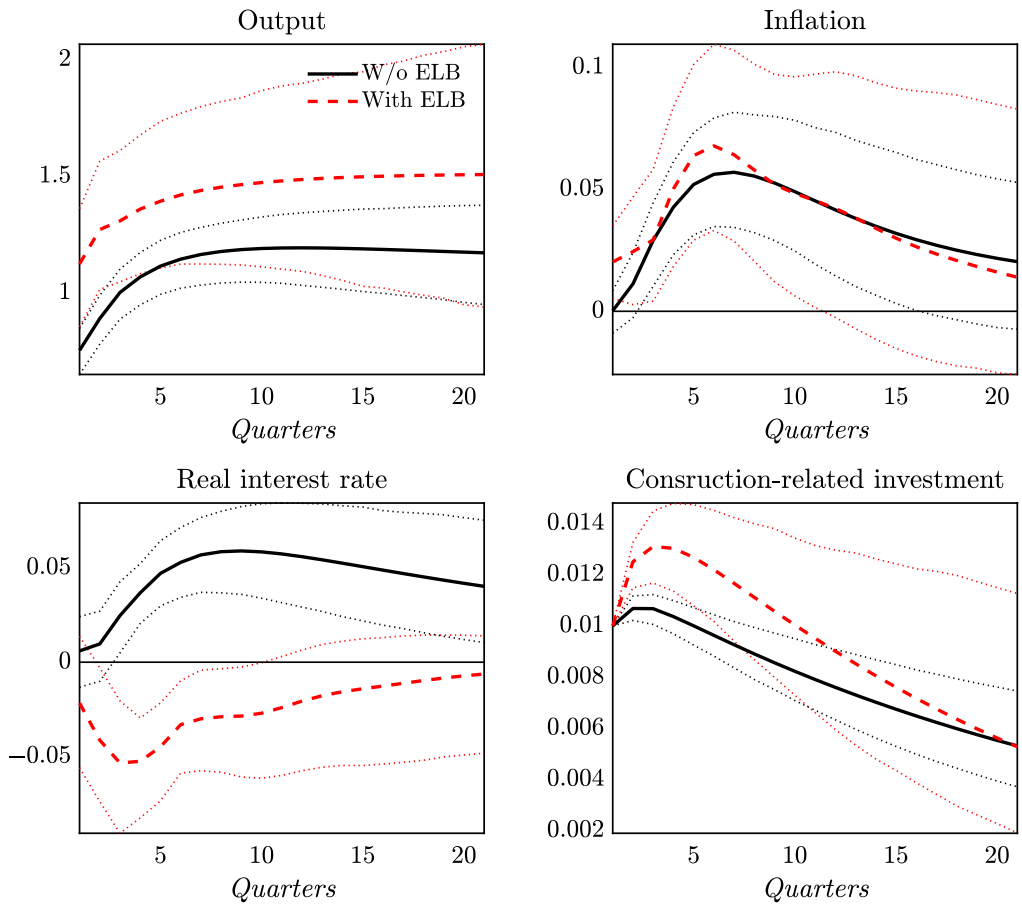

Notes: The shock is scaled to be $1 \%$ of GDP. The dotted lines reflect the $90 \%$ confidence interval. Units are in percentages for output and government spending and in percentage points for inflation and the real interest rate.

FigURE 8. Cumulative multipliers following a construction-related investment shock.

lag length to $K=2 .^{29}$ The responses to the construction- and equipment-related investment shocks are shown in Figures 8 and 9.

The figures show that the output response to both shocks is positive, regardless of whether the ELB is binding or not. However, only for shocks to constructionrelated public investments do we find that the output response is significantly higher when the economy is at the ELB than when it is not. Intuitively, to the extent that construction projects (e.g. building a new highway or bridge) take time to finalize, the deflationary effects associated with the investment through lower marginal costs are pushed into the future. This implies that the immediate positive effect of the investment shock, which works through increases in aggregate demand, dominates and thereby pushes up inflation. As Figure 8 shows, construction-related government investment shocks lead to a significantly positive response of inflation and a significantly negative response of the real interest rate when the ELB is binding. In contrast, a shock to equipment-related government investment at the ELB does neither yield a significant response of inflation nor the real interest rate, as shown in Figure 9 (the responses away from the ELB, however, are significant). Since these types of investments have a more immediate 

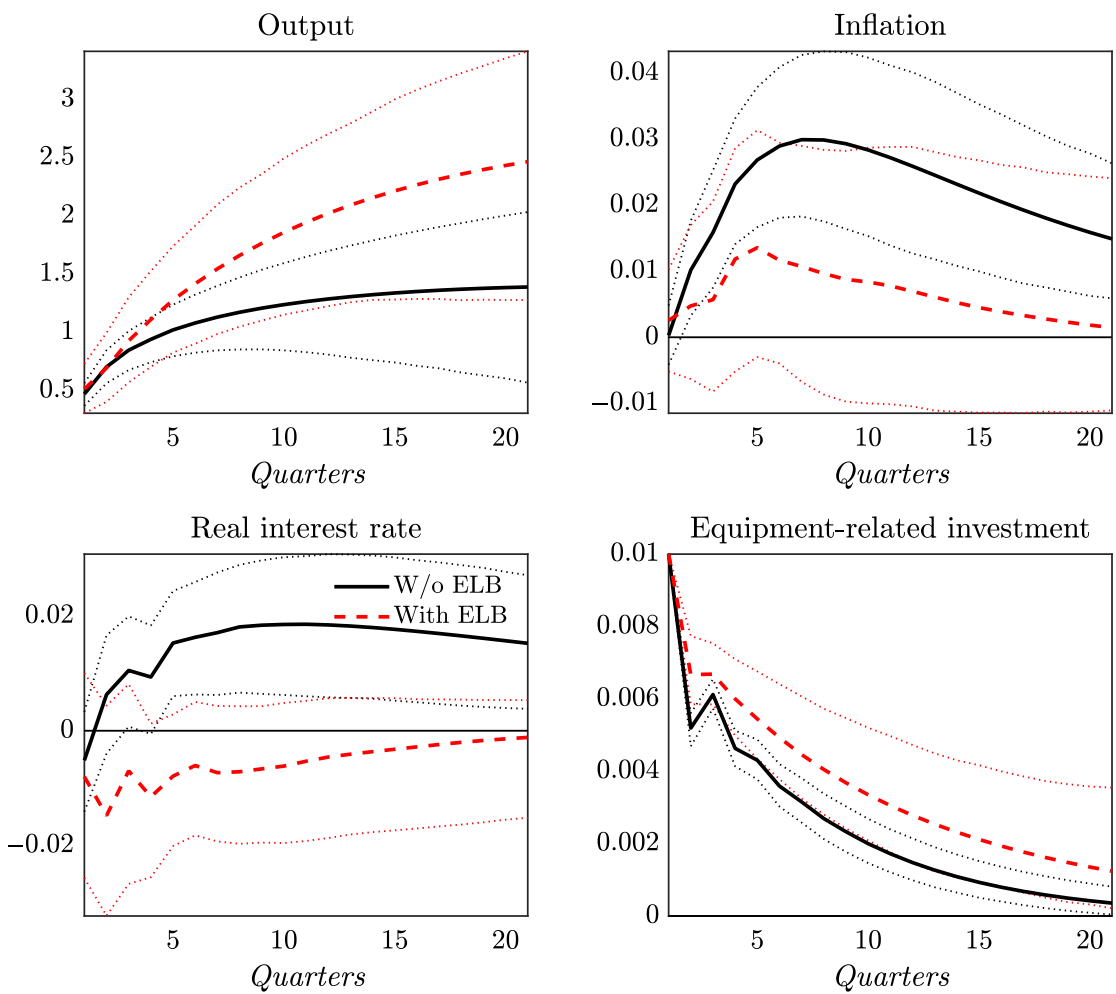

Notes: The shock is scaled to be $1 \%$ of GDP. The dotted lines reflect the $90 \%$ confidence interval. Units are in percentages for output and government spending and in percentage points for inflation and the real interest rate.

FIGURE 9. Cumulative multipliers following an equipment-related investment shock.

effect on productive capital, their dampening effect on current marginal costs and inflation is transmitted more promptly. Consequently, there is less scope for inflation to rise or the real interest rate to fall when the ELB is binding.

In sum, the effects of total government investment shocks at the ELB shown in Figure 7 seem to be driven by construction-related investments for which shortterm negative supply-side effects appear absent. Table 2 reports the cumulative fiscal multipliers at different horizons, across the two different regimes and for the different government spending categories.

\subsection{Robustness Analysis}

5.3.1. Changing the definition of the ELB proxy. Although the results presented in Figures 6 and 7 are consistent with conventional Keynesian theory, they depend on our definition of ELB spells. In order to test whether our results are robust, we estimate the government consumption and investment multipliers for different definitions of the ELB. 
TABLE 2. Estimates for the cumulative fiscal multipliers.

\begin{tabular}{lcc}
\hline & Without ELB & With ELB \\
\hline Government consumption shock & & \\
Impact multiplier & $0.3^{*}$ & $0.91^{*}$ \\
After 1 year & $0.28^{*}$ & $1.42^{*}$ \\
After 3 years & 0.33 & $2.01^{*}$ \\
After 5 years & 0.19 & $1.48^{*}$ \\
Government investment shock & & \\
Impact multiplier & $0.51^{*}$ & $0.72^{*}$ \\
After 1 year & $0.74^{*}$ & $0.95^{*}$ \\
After 3 years & $0.82^{*}$ & $1.12^{*}$ \\
After 5 years & $0.83^{*}$ & $1.19^{*}$ \\
Construction-related government investment shock & \\
Impact multiplier & $0.75^{*}$ & $1.12^{*}$ \\
After 1 year & $1.07^{*}$ & $1.36^{*}$ \\
After 3 years & $1.19^{*}$ & $1.49^{*}$ \\
After 5 years & $1.17^{*}$ & $1.51^{*}$ \\
Equipment-related government investment shock & \\
Impact multiplier & $0.47^{*}$ & $0.51^{*}$ \\
After 1 year & $0.94^{*}$ & $1.11^{*}$ \\
After 3 years & $1.29^{*}$ & $2.02^{*}$ \\
After 5 years & $1.38^{*}$ & $2.43^{*}$ \\
\hline
\end{tabular}

Notes: Shocks are scaled to be $1 \%$ of GDP. * denotes statistical significance at the $10 \%$ level.

In particular, recall that ELB episodes were defined as periods during which the nominal interest rate is below $\mathcal{T}$ percent for $\mathcal{D}$ consecutive quarters, with $\mathcal{T}=1$ and $\mathcal{D}=4$, see equation (21). This section shows how altering either $\mathcal{D}$ or $\mathcal{T}$ affects the estimated impact fiscal multipliers and how the results relate to our theoretical benchmark. Throughout, we use the same panel VAR model as before, as given by equation (23), and keep the number of lags fixed at $K=5$ for the model with only government consumption, and $K=6$ for the model with both government consumption and government investment. In doing so, we iterate only along one dimension which allows us to isolate the effects of either the ELB duration or the ELB threshold.

Figure 10 plots the estimated government consumption multipliers as a function of either $\mathcal{D}$ or $\mathcal{T}$, along with the baseline multiplier in normal times when the ELB is not binding (solid horizontal line). In the left-hand side panel, the threshold value for the nominal interest rate is kept at $\mathcal{T}=1 \%$, while the duration of the ELB, $\mathcal{D} \in[1,15]$, varies along the horizontal axis. The results suggest that government consumption shocks have positive output responses on impact, with the responses being higher for more prolonged ELB episodes, that is, for higher values of $\mathcal{D}$. These results are in line with our theoretical benchmark, and the results are shown in Figure 3: when the period during which monetary policy is 

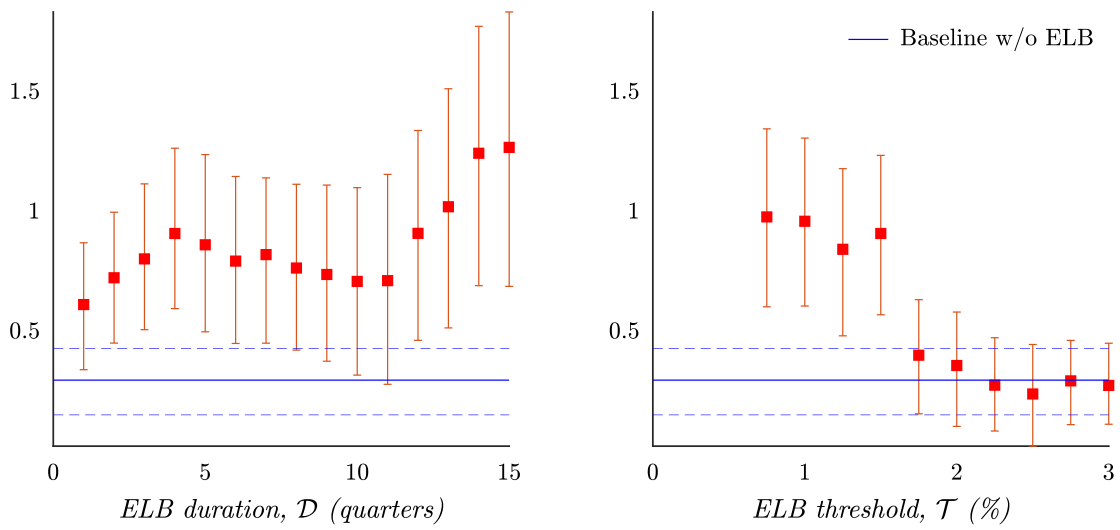

Notes: The ELB proxy refers to episodes when the nominal policy rate is below $\mathcal{T}$ percent for $\mathcal{D}$ consecutive quarters, see equation (21). In the left-hand side panel, we keep the threshold fixed at $\mathcal{T}=1 \%$; in the right-hand side panel, we keep the ELB duration fixed at $\mathcal{D}=4$ quarters. The whiskers reflect the $90 \%$ confidence interval. Units are in percentages.

FIGURE 10. Impact government consumption multiplier and the role of $\mathcal{D}$ and $\mathcal{T}$.

constrained is extended, the crowding-in effects of fiscal policy are potentially larger. Indeed, whereas the impact multiplier under our baseline assumption of $\mathcal{D}=4$ is about 0.9 , it rises to 1.2 under the assumption that the ELB lasts for $\mathcal{D}=15$ quarters.

The right-hand side panel of Figure 10 shows estimates of the impact multiplier under different assumptions for the threshold value for the nominal interest rate, $\mathcal{T}$, while keeping the ELB duration fixed at $\mathcal{D}=4$ consecutive quarters. We choose to perform this robustness exercise for two reasons. First, recall that $\mathcal{T}$ is a proxy for the level at which the nominal interest is bound by the ELB. Because our baseline choice for $\mathcal{T}$ is (somewhat) arbitrary and because the true value for $\mathcal{T}$ may differ across countries, it follows that considering alternative threshold values is warranted. Second, what matters for the size of the fiscal multiplier is not only that the nominal interest rate remains constant, but that it is expected to remain unresponsive to economic conditions for a prolonged period of time. This is more likely to be the case at the ELB than away from the ELB in which case the central bank has more scope to adjust its policy rate in response to shocks. Hence, the level at which the nominal interest rate remains constant matters. The results shown in Figure 10 support this conjecture: only when the nominal interest rate is constant and relatively low, and therefore more likely to be bound by the ELB, do we find significantly higher government spending multipliers compared to the baseline regime. In fact, with $\mathcal{T}$ sufficiently high, we obtain impact multipliers that are essentially the same as those found in the absence of a binding ELB.

Figure 11 shows the estimates of the government investment multipliers as a function of either $\mathcal{D}$ or $\mathcal{T}$. The figure suggests that longer ELB spells (lefthand side panel) and lower ELB thresholds (right-hand side panel) are associated with greater impact multipliers, on average. Moreover, and consistent with our 

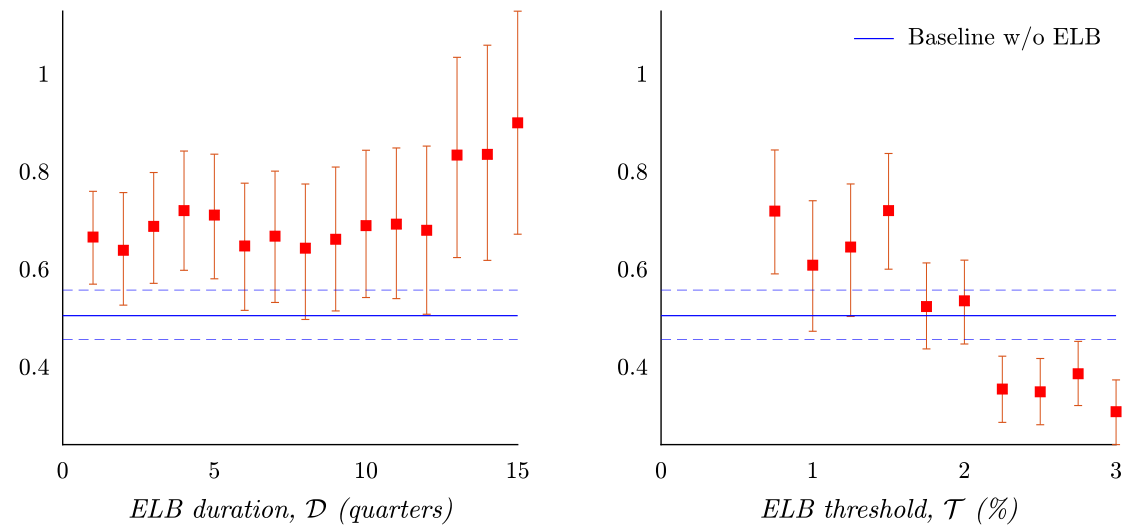

Notes: See notes to Figure 10.

FIGURE 11. Impact government investment multiplier and the role of $\mathcal{D}$ and $\mathcal{T}$.
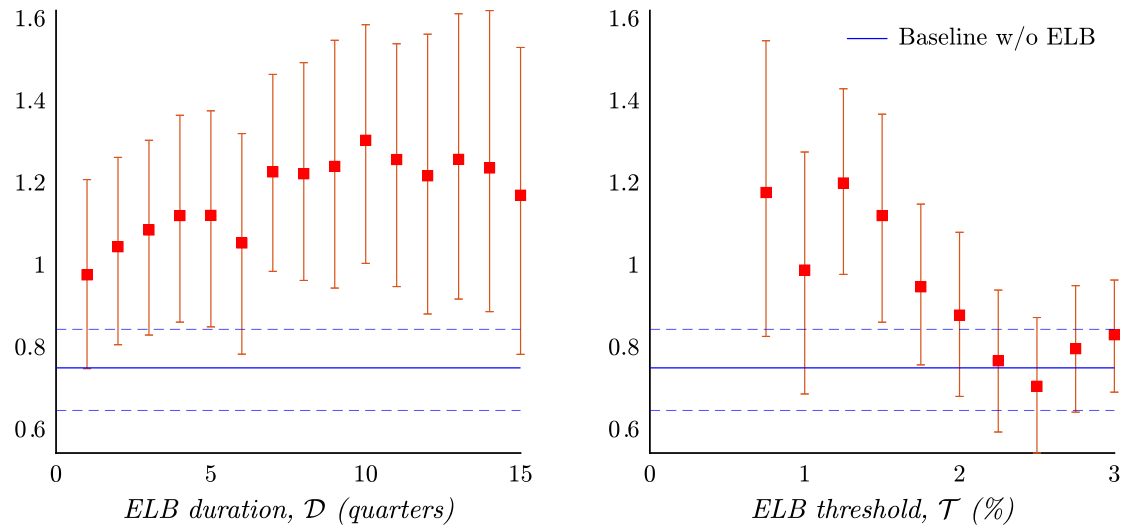

Notes: See notes to Figure 10.

FIGURE 12. Impact construction-related investment multiplier and the role of $\mathcal{D}$ and $\mathcal{T}$.

theoretical exercise in Section 3, the ELB spell has a more enhancing effect on the government investment multiplier when investment is in construction rather than equipment, as shown by Figures 12 and 13.

5.3.2. Controlling for anticipation effects. Because we apply our VAR model to quarterly data, our results may be biased due to anticipation effects as agents may foresee the fiscal shocks and adjust their behavior accordingly [Yang (2005) and Leeper, Walker and Yang (2013)]. One approach the literature has suggested to deal with these potential anticipation effects is to include forwardlooking variables to the VAR model. Intuitively, such variables might be able to capture agents' expectations regarding future fiscal innovations. Yang (2007), 

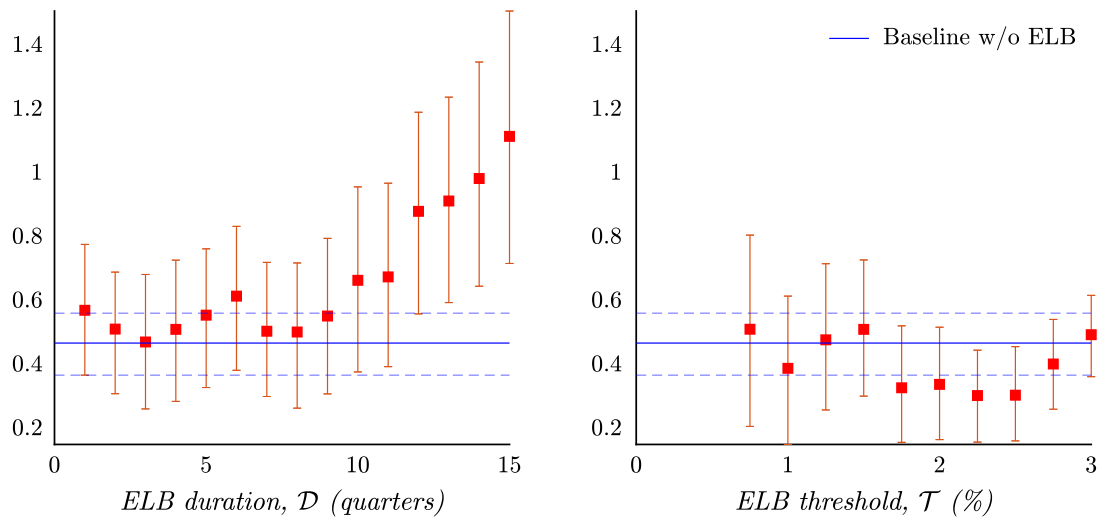

Notes: See notes to Figure 10.

FIGURE 13. Impact equipment-related investment multiplier and the role of $\mathcal{D}$ and $\mathcal{T}$.

for instance, shows that the response to tax innovations estimated from a standard VAR model hinges on the inclusion of short-term interest rates and prices, which suggests that these variables contain information about the macroeconomic impact of future fiscal policy changes. Although our baseline model already includes the real interest rate, which may account for anticipation effects to some extent, we augment the model by including the 10-year sovereign bond yield that may hold additional information about the expected future path of fiscal variables not captured by the short-term interest rate and future inflation. ${ }^{30}$

We add the sovereign bond yield, taken from Datastream, to our baseline VAR model such that it enters the model last. Alternative orderings, however, do not qualitatively alter the results. The cumulative fiscal multipliers resulting from this augmented model are shown in Figure 14. Again we find that for both shocks to government consumption and investment, the output response is positive and higher when the ELB binds than when it does not. The difference in output responses across the two states is also significant, even at longer horizons in the case of government consumption shocks.

5.3.3. Excluding the euro area countries from the sample. The inclusion of euro area countries in our sample might bias our estimates, as our identification strategy might mistakenly capture the influence of the monetary regime rather than that of the ELB on the effects of fiscal policy. In particular, as shown in Figure 5, the euro area countries included in our sample only experienced ELB spells when they were part of the euro area, that is, after 1999, during which they faced a quasi fixed exchange rate regime. ${ }^{31}$ Before EMU, when these countries faced a more flexible exchange rate regime, interest rates were not at the ELB in these countries. So there is an identification problem, since the effects of a fixed exchange rate regime on the fiscal multiplier have been found to be similar to the effects of the ELB [Corsetti et al. (2012) and Ilzetzki et al. (2013)]. Particularly, the monetary 

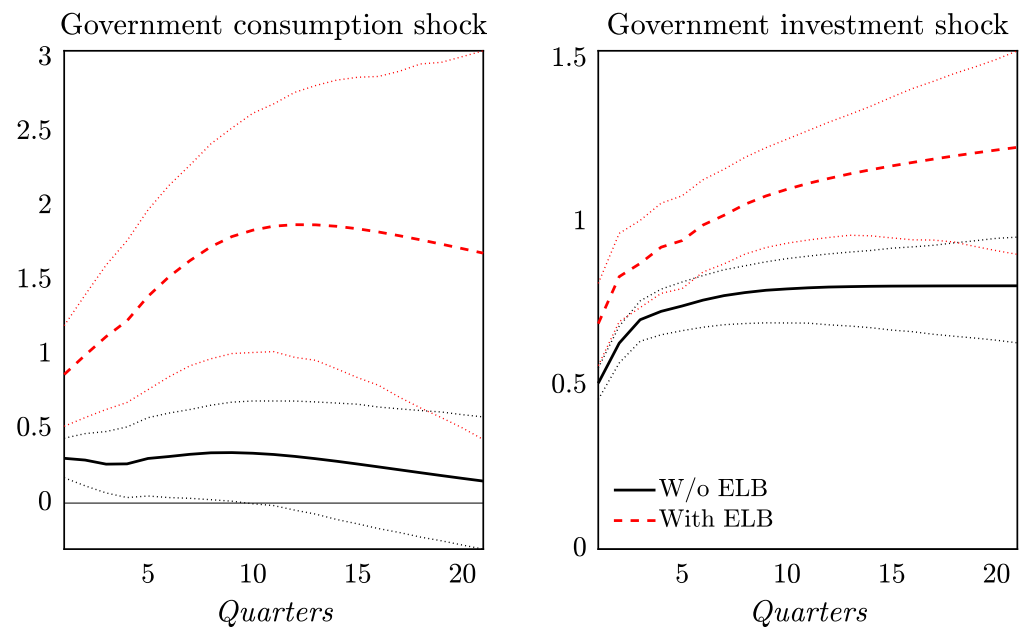

Notes: The shocks are scaled to be $1 \%$ of GDP. The dotted lines reflect the $90 \%$ confidence interval. Units are in percentages.

FIGURE 14. Cumulative fiscal multipliers when augmenting the VAR model with the 10year sovereign bond yield.

authority under a fixed exchange rate regime will not counteract an expansionary fiscal shock by raising the interest rate, since it is committed to protect the exchange rate peg. Therefore, the crowding-out effects of fiscal policy are likely to be weaker under fixed exchange rates than under flexible exchange rates, since the interest rate is less responsive under the former regime.

In order to control for the possible effects of a change in the monetary regime, we exclude the members of the euro area, except Germany, from the sample in the next robustness exercise. We keep Germany in the sample, because, given Germany's relatively large size within the euro area, fiscal shocks in Germany are probably large enough to provoke a change in the common central bank's policy rate provided the ELB is not binding. For this smaller sample of countries, and using the model specified by equation (23) and the ELB definition specified by equation (21), we obtain estimates for the cumulative government consumption and investment multipliers.

The results, as shown in Figure 15, suggest that our main findings remain intact after excluding most euro area countries from the sample. ${ }^{32}$ As before, we find that the response of GDP to both a government consumption shock and government investment shock is significantly stronger in the presence of a binding ELB than in its absence.

5.3.4. Controlling for the business cycle. As a final robustness check, we add an additional constraint on the output gap to the definition of the ELB in order to control for the potential effects of changes in the business cycle on the size of the fiscal multiplier. As shown by Auerbach and Gorodnichenko (2012b) and Canzoneri et al. (2016), among others, the effects of fiscal policy may vary 

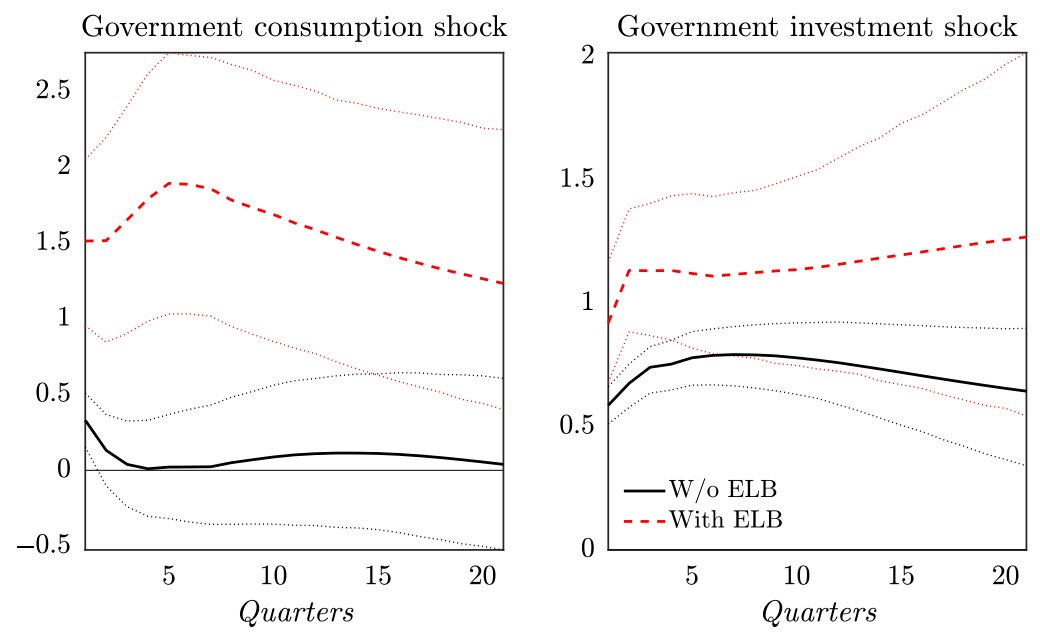

Notes: The shocks are scaled to be $1 \%$ of GDP. The dotted lines reflect the $90 \%$ confidence interval. The results are generated using a smaller sample of countries, which excludes all euro area countries, except for Germany. Units are in percentages.

FIGURE 15. Cumulative fiscal multipliers when using a smaller country sample.

depending on the state of the economy. During a crisis, for instance, many households and firms might be credit constrained due to elevated risk premia and borrowing costs, implying that their marginal propensity to consume is relatively high. As a consequence, the fiscal multiplier is likely to be higher in times of recession than under more benign economic conditions. As reported by Auerbach and Gorodnichenko (2012b), multipliers are well above unity during recessions, yet are found to be between 0 and 0.5 during expansions.

One could imagine that ELB episodes typically take place when the economy faces a substantial amount of slack, as monetary policy responds to slack by actively reducing the interest rate. Therefore, a potential identification issue arises since both the ELB and economic slack are expected to push the multiplier in the same direction. To solve this issue, we now define ELB episodes as those during which the nominal interest rate has been below $1 \%$ for the last 4 consecutive quarters and the output gap has been positive for the last 3 consecutive quarters. Letting $O G_{n, t}$ denote a measure of the output gap for country $n$ at time $t$, the definition of the ELB indicator, $\mathcal{I}_{n, t}$, can then be changed accordingly:

$$
\mathcal{I}_{n, t}= \begin{cases}1 & \text { if }\left\{R_{n, t-s} \mid s=0,1,2,3\right\}<1 \% \text { and }\left\{O G_{n, t-s} \mid s=0,1,2\right\}>0 \\ 0 & \text { otherwise. }\end{cases}
$$

Using this modified definition of the ELB proxy, the effects of the ELB on the size of the multiplier can be estimated without being contaminated by the effects of economic slack. ${ }^{33}$

The top panel of Figure 16 shows the output gap for our sample of advanced economies during 1997Q1-2017Q4 (during which data for all countries are 
(a)

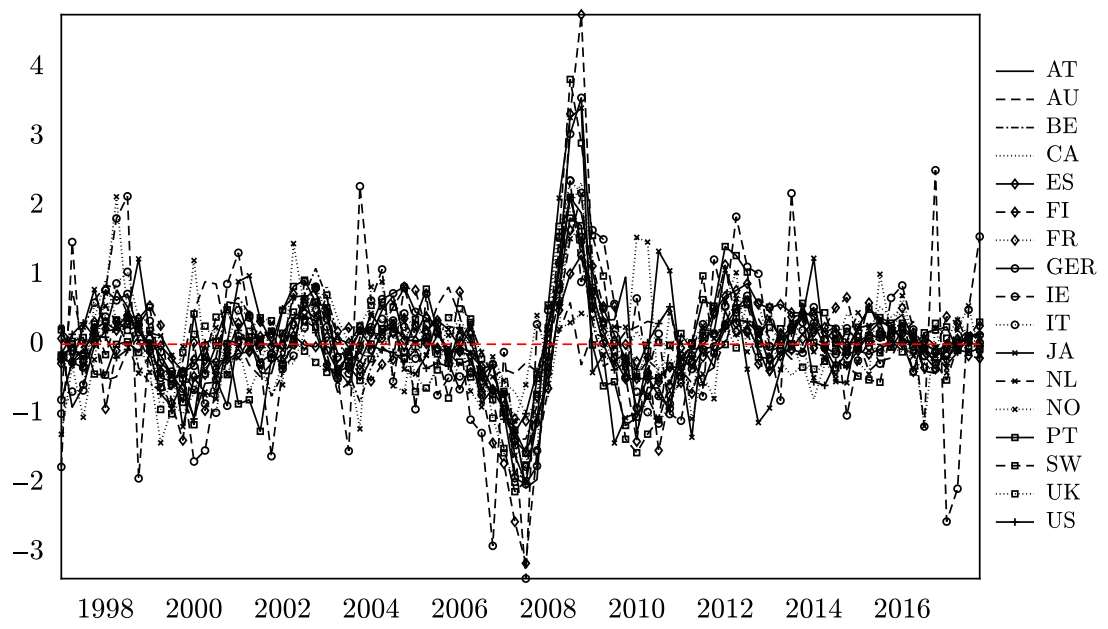

(b)

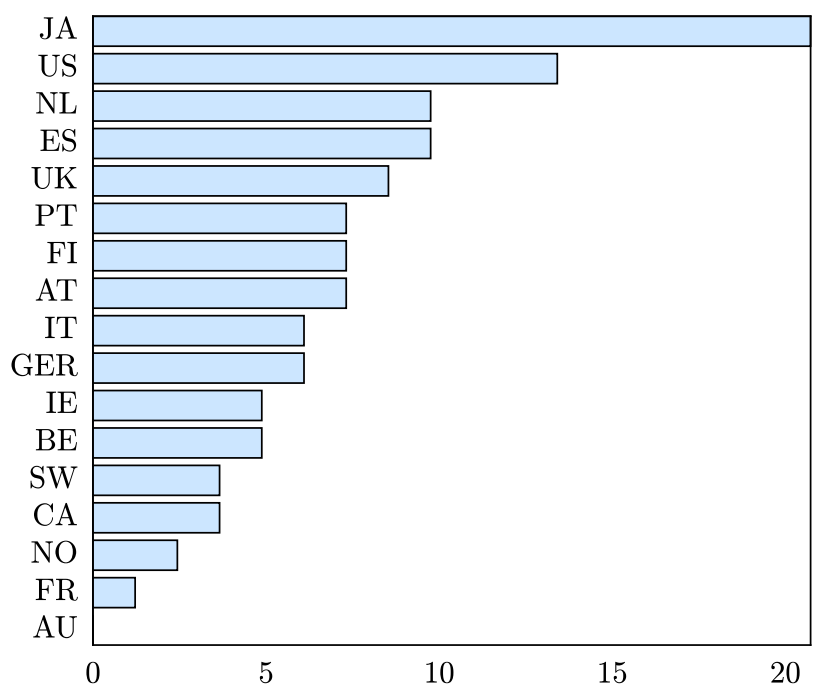

Source: Datastream, OECD Quarterly National Accounts Database and own calculations.

Notes: Countries are assumed to face the ELB when the nominal interest rate has been below $1 \%$ for the last four consecutive quarters and the output gap has been positive for the last 3 consecutive quarters, see equation (24).

FigURE 16. Output gap and ELB incidence. (a) Output gap (\%), (b) Fraction of time spent at ELB (\%) under additional output-gap restriction, 1997Q1-2017Q4. 

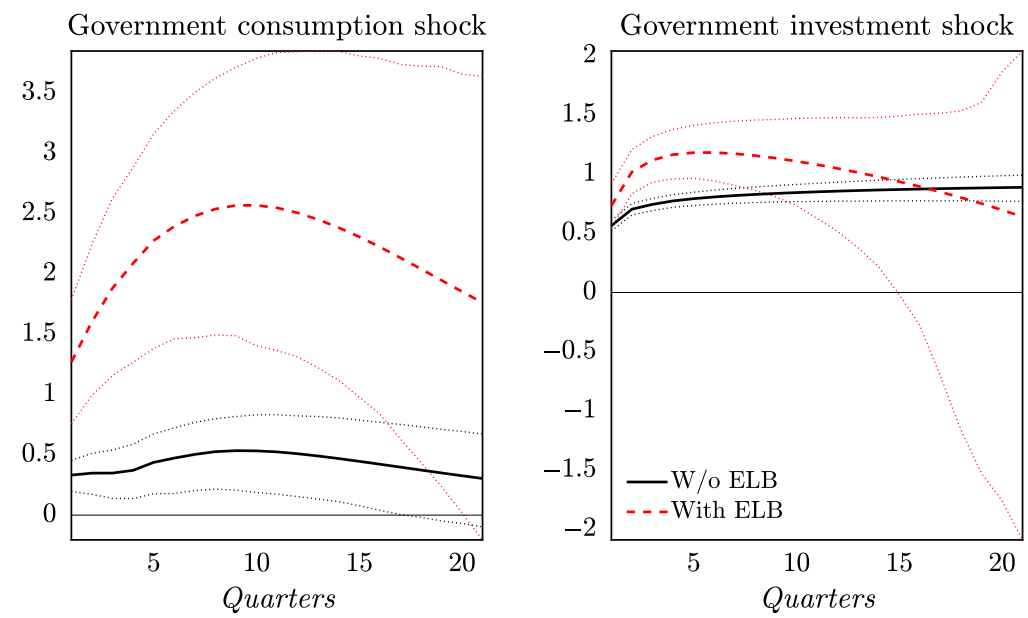

Notes: The shocks are scaled to be $1 \%$ of GDP. The dotted lines reflect the $90 \%$ confidence interval. The ELB is defined according to equation (24). Units are in percentages.

FIGURE 17. Cumulative fiscal multipliers when using additional output-gap restriction.

available), along with the output gap threshold used in the modified definition of the ELB proxy (horizontal dashed line). We calculate the output gap as the percentage deviation of real GDP from its trend. Following Auerbach and Gorodnichenko (2012a), we obtain the latter by applying a 2-year moving average Hodrick-Prescott filter, with a smoothing parameter of $\lambda=10,000$. The reason for using the moving average HP filtered trend is to capture possible time variation in the trend across countries. ${ }^{34}$

Compared to Figure 5, Figure 16 suggests that prolonged spells of low interest rates did indeed coincide with negative output gaps on some occasions. As a consequence, the fraction of time spent at the ELB according to the new definition of the ELB proxy is, for all countries, less than under the old definition of the ELB proxy, which does not include the positive output-gap restriction (see bottom panel of Figure 16). In particular, under the old definition of the ELB, we observed a total of 373 instances for which $\mathcal{I}_{n, t}=1$; under the modified definition of the ELB, this number drops to 96.

Figure 17 shows the estimates for the cumulative government consumption and investment multipliers, while controlling for the effects of the business cycle using the modified definition of the ELB (24). The figure suggests that the response of GDP to a government consumption shock is still significantly higher in the presence of a binding ELB than in its absence (left-hand side panel). Moreover, we find a maximum cumulative multiplier of 2.6, which is larger than under the baseline specification where we did not control for the business cycle. The output response to a government investment shock is also more pronounced when the economy is at the ELB than when it is not (right-hand side panel), with a peak cumulative multiplier of around 1.2, which is similar to our baseline result. 


\section{CONCLUSION}

Nowadays, fiscal policy is often called upon to support monetary policy, which is severely constrained due to interest rates being at their ELB. Although theoretical analyses suggest that fiscal policy might be more effective when the economy faces the ELB than under normal circumstances, there is only limited empirical evidence in support of this prediction.

In this paper, we estimate the effects of government consumption and investment shocks during prolonged episodes of low interest rates, which we consider as a proxy for the ELB. Using a panel VAR model for 17 advanced countries, in which we include real government spending, output, inflation, and the real interest rate, we find that both the cumulative government consumption and investment multipliers are significantly higher (and exceed unity) when interest rates are persistently low. Distinguishing between construction- and equipmentrelated government investment, we find that only the former raises output by significantly more when the ELB binds. Therefore, the overall effects of government investment on output at the ELB seem to be driven by construction-related government investment for which short-term negative supply-side effects appear absent.

Our findings are robust for using different threshold values for the nominal interest rate or the length of the period with low interest rates to proxy the ELB. Also, controlling for the exchange rate regime, potential anticipation effects and the business cycle does not affect our main conclusions. Our results therefore support pleas by several central bankers and other policymakers to give fiscal policy a more important role in stabilizing the economy, provided fiscal policy sustainability allows doing so.

\section{SUPPLEMENTARY MATERIAL}

To view supplementary material for this article, please visit http://doi.org/10. $1017 /$ S1365100520000097.

\section{NOTES}

1. Similarly, then-ECB-President Draghi argued in his speech at Jackson Hole in 2014 that "...it would be helpful if fiscal policy could play a greater role alongside monetary policy, and I believe there is scope for this, while taking into account our specific initial conditions and legal constraints." [Draghi (2014)].

2. Eggertsson (2011) refers to this negative supply-side effect of fiscal policy as the "paradox of toil".

3. We also address the potential projection bias associated with VAR models and verify that LocalProjection-based impulse response functions yield similar results as those based on the VAR model.

4. The role of supply-side policies that raise future productivity is also discussed in FernándezVillaverde et al. (2014). They show that structural reforms generate strong wealth effects at the ELB, thereby raising output and consumption contemporaneously, provided the associated productivity gains (that lower inflation) do not materialize immediately, but somewhere in the future. 
5. There are also many studies that focus more broadly on the state-dependence of fiscal policy, see, for example, Auerbach and Gorodnichenko (2012a), Auerbach and Gorodnichenko (2012b), Corsetti et al. (2012), Ilzetzki et al. (2013), and Canzoneri et al. (2016).

6. Ellahie and Ricco (2017) also estimate the effects of government spending shocks in the USA and distinguish between aggregate government purchases and government investment components, yet do not condition on the ELB.

7. Other papers studying fiscal-monetary policy interactions, yet abstracting from ELB events, are Davig and Leeper (2011) and Leeper et al. (2017), among others.

8. A similar method is used by Christiano et al. (2011).

9. The inclusion of investment adjustment costs allows the model to be more well behaved when imposing longer ELB spells, thereby also allowing for a more straightforward comparison across ELB and non-ELB regimes.

10. Relaxing the assumption of a period balanced budget rule and allowing, instead, for short-run fluctuations in the budget deficit does not alter the results in any qualitative sense.

11. See Ji and Xiao (2016) for a regime-switching approach of modeling the ELB in a similar dynamic macroeconomic model.

12. In what follows, we refer to the impact multiplier as simply the multiplier. However, we shall also present results for the cumulative multiplier, the definition of which is given below.

13. We also considered other proxies for the ELB, such as an indicator for periods when inflation drops below $1 \%$ or $2 \%$ [see, for instance, Qazizada and Stockhammer (2015)], but decided that they are problematic. For instance, this indicator would equal 1 for the Netherlands in the early and mid1980 s, while interest rates at the time were well above $5 \%$.

14. In a recent study by the IMF (2017), in which the spillover effects of fiscal policy are studied, a similar scheme is applied to identify ELB episodes. In particular, the ELB is considered to be binding when the short-term interest rate is below the 25 th percentile of the relevant cross-country distribution. The study finds similar results when using an absolute threshold for the interest rate, as employed in the present paper.

15. We also considered alternative timing conventions whereby we identify ELB spells as periods when interest rates are below $1 \%$ for the next (rather than previous) 4 consecutive quarters, and intermediate cases, in order to account for potentially forward-looking behavior. The results under these alternative timing conventions are very similar to our baseline results and are available upon request.

16. For this reason, we also exclude the euro area countries from the sample in one of our robustness exercises. Using this smaller sample of countries does not, however, qualitatively change our results.

17. Other common restrictions are long-run restrictions [Blanchard and Quah (1993)], theory-based restrictions [Blanchard and Perotti (2002)], and sign restrictions [Mountford and Uhlig (2009)].

18. We also estimated a model where we replace the real interest rate by the nominal interest rate. The results from this alternative model are similar to our baseline results. The nominal interest rate response to a government investment shock is positive when the ELB is not binding, and only weakly positive when the ELB is binding. Following a government consumption shock, the nominal interest rate response is insignificant away from the ELB and slightly negative at the ELB. These results are displayed in Figure 8 in the online Appendix.

19. In Figure 1 in the online Appendix, we show the results for using an alternative model in which we replace GDP by a measure for "private GDP," that is, GDP minus the government expenditures component [see Beetsma and Giuliodori (2011), for a similar approach]. This alternative specification, in which the assumption of a zero-contemporaneous response of government spending to economic activity is relaxed, yields similar results.

20. The Cholesky decomposition assumes that $A$ has the following form:

$$
A=\left[\begin{array}{cccc}
1 & 0 & 0 & 0 \\
a_{21} & 1 & 0 & 0 \\
a_{31} & a_{32} & 1 & 0 \\
a_{41} & a_{42} & a_{43} & 1
\end{array}\right],
$$

and that $C$ is the identity matrix. 
21. Using alternative lag structures gives similar results, which are available on request.

22. For a discussion on the merits of the Local Projection method compared to the standard VAR method, see Ramey and Zubairy (2018).

23. We also used the three-months market rate to both define the ELB in (21) and construct the ex-post real interest rate $r_{n, t}$, rather than the policy rate set by the central bank. However, the results, reported in Figure 3 in the online Appendix, do not change much under this alternative specification.

24. This long-run "fiscal neutrality" can also be explained by the rise in future taxes needed to finance the fiscal expansion [Uhlig (2010)].

25. In Figure 2 in the online Appendix, we show the responses to the government spending shocks for the full sample, that is, in times when the ELB is both binding and not binding. As expected, the estimated cumulative fiscal multiplier using the full sample lies in between those shown in Figure 6.

26. Since many observations that include a binding ELB pertain to Japan (see Figure 5), we also excluded Japan from our sample in one of our robustness exercises. The results, reported in Figure 6 in the online Appendix, show that the cumulative fiscal multiplier is still significantly higher when the ELB is binding than when it is not.

27. Although we apply the same Cholesky decomposition in this model, we also experimented with a modified restriction where we assume a zero-contemporaneous response of government consumption to government investment shocks (such that the upper-left corner of the $A$ matrix is diagonal). The results (available on request) under this modified restriction are almost identical to our baseline results.

28. The response of government consumption to the government investment shock (not shown) is slightly positive away from the ELB and insignificant at the ELB (results available on request).

29. Although the AIC suggests an optimal lag length of 5, we only use 2 lags to preserve the number of observations, which for the equipment- and construction-related government investment series is somewhat lower than for the aggregate government investment series. Using 5 lags produces similar, yet less significant results. In any case, the results remain significant within a $68 \%$ confidence interval band.

30. We also considered using government debt and the nominal stock price index as additional variables. The latter has been shown by Forni and Gambetti (2010) to be particularly helpful in correctly identifying and estimating fiscal shocks. The model that includes either of these additional variables delivers similar results and are available upon request. Furthermore, as discussed by Beetsma and Giuliodori (2011), anticipation effects could also be potentially accounted for when using annual data, as fiscal shocks are less likely to be anticipated in advance when they occur in the next year rather than the next quarter. However, using annual data also weakens the exogeneity assumption followed here of fiscal policy not responding to economic conditions within the same period as the fiscal shock. Although the results based on annual data are qualitatively similar as our baseline results, we do not report them here due to this latter issue.

31. Since the euro is free to fluctuate against other currencies, euro area countries only face a fixed exchange rate within the euro area. Hence, the term quasi fixed exchange rate regime.

32. This also holds when the opposite is true, that is, excluding all countries except the aggregate euro area (including 19 euro area countries, with the sample starting from 1999). The corresponding results are shown in Figure 10 in the online Appendix. In a related paper, Amendola et al. (2018) show that the government spending multiplier is higher at the ELB for a panel of euro area countries.

33. Using the unemployment gap (based on OECD estimates) rather than the output gap to distinguish between periods with ample and limited economic slack does not alter the baseline results (see Figure 9 in the online Appendix).

34. As discussed in Auerbach and Gorodnichenko (2012a), the large smoothing parameter is used to prevent the trend from following cyclical fluctuations too much. Our results are, however, robust to alternative values for the smoothing parameter, such as $\lambda=1600$, which is more commonly used for quarterly data. Results are available upon request.

35. Earlier studies applying the LP method to estimate fiscal multipliers either use government spending shocks derived from a similar VAR model employed here or from a narrative dataset of exogenous fiscal policy changes, or both. See, for instance, Broner et al. (2018) and Ramey and Zubairy (2018). 


\section{REFERENCES}

Albertini, J., A. Poirier and J. Roulleau-Pasdeloup (2014) The composition of government spending and the multiplier at the zero lower bound. Economics Letters 122(1), 31-35.

Almunia, M., A. Benetrix, B. Eichengreen, K. H. O’Rourke and G. Rua (2010) From great depression to great credit crisis: Similarities, differences and lessons. Economic Policy 25(62), 219-265.

Amendola, A., M. Di Serio and M. Fragetta (2018) The Government Spending Multiplier at the Zero Lower Bound: Evidence from the Euro Area, CELPE Discussion Papers 153.

Aruoba, S. B., P. Cuba-Borda and F. Schorfheide (2018) Macroeconomic dynamics near the ZLB: A tale of two equilibria. Review of Economic Studies 85, 87-118.

Auerbach, A. J. and Y. Gorodnichenko (2012a) Fiscal multipliers in recession and expansion. In: A. Alesina and F. Giavazzi (eds.), Fiscal Policy after the Financial crisis, Chicago: University of Chicago Press, pp. 63-98.

Auerbach, A. J. and Y. Gorodnichenko (2012b) Measuring the output responses to fiscal policy. American Economic Journal: Economic Policy 4(2), 1-27.

Baxter, M. and R. G. King (1993) Fiscal policy in general equilibrium. American Economic Review 83(3), 315-334.

Beetsma, R. and M. Giuliodori (2011) The effects of government purchases shocks: Review and estimates for the EU. The Economic Journal 121(550), 4-32.

Beetsma, R., M. Giuliodori and F. Klaassen (2008) The effects of public spending shocks on trade balances and budget deficits in the European Union. Journal of the European Economic Association 6(2-3), 414-423.

Blanchard, O. and R. Perotti (2002) An empirical characterization of the dynamic effects of changes in government spending and taxes on output. Quarterly Journal of Economics 117, 1329-1368.

Blanchard, O. J. and D. Quah (1993) The dynamic effects of aggregate demand and supply disturbances. American Economic Review 83(3), 653-658.

Blinder, A., M. Ehrman, J. de Haan and D. Jansen (2017) Necessity as the mother of invention: Monetary policy after the crisis. Economic Policy 32(92), 707-755.

Boehm, C. E. (2019) Government consumption and investment: Does the composition of purchases affect the multiplier? Journal of Monetary Economics (forthcoming).

Boneva, L. M., R. Anton Braun and Y. Waki (2016) Some unpleasant properties of loglinearized solutions when the nominal rate is zero. Journal of Monetary Economics 84, 216-232.

Bouakez, H., M. Guillard and J. Roulleau-Pasdeloup (2017) Public investment, time to build, and the zero lower bound. Review of Economic Dynamics 23, 60-79.

Broner, F., D. Clancy, A. Martin and A. Erce (2018) Fiscal Multipliers and Foreign Holdings of Public Debt, Working Paper No. 30, European Stability Mechanism.

Calvo, G. A. (1983) Staggered prices in a utility-maximizing framework. Journal of Monetary Economics 12(3), 383-398.

Canzoneri, M., F. Collard, H. Dellas and B. Diba (2016) Fiscal multipliers in recessions. The Economic Journal 126(590), 75-108.

Carlstrom, C. T., T. S. Fuerst and M. Paustian (2014) Fiscal multipliers under an interest rate peg of deterministic versus stochastic duration. Journal of Money, Credit and Banking 46(6), 1293-1312.

Christiano, L. J., M. Eichenbaum and C. L. Evans (1999) Monetary policy shocks: What have we learned and to what end? In: J. Taylor and M. Woodford (eds.), Handbook of Macroeconomics, Vol. 1, Amsterdam: Elsevier, pp. 65-148.

Christiano, L., M. Eichenbaum and S. Rebelo (2011) When is the government spending multiplier large? Journal of Political Economy 119(1), 78-121.

Coenen, G., C. J. Erceg, C. Freedman, D. Furceri, M. Kumhof, R. Lalonde, D. Laxton, J. Lindé, A. Mourougane, D. Muir, S. Mursula, C. De Resende, J. Roberts, W. Roeger, S. Snudden, M. Trabandt and J. in't Veld (2012) Effects of fiscal stimulus in structural models. American Economic Journal: Macroeconomics 4(1), 22-68.

Cogan, J. F., T. Cwik, J. B. Taylor and V. Wieland (2010) New Keynesian versus old Keynesian government spending multipliers. Journal of Economic Dynamics and Control 34(3), 281-295. 
Corsetti, G., A. Meier and G. J. Müller (2012) What determines government spending multipliers? Economic Policy 27(72), 521-565.

Crafts, N. and T. C. Mills (2013) Rearmament to the rescue? New estimates of the impact of "Keynesian" policies in 1930s' Britain. The Journal of Economic History 73(4), 1077-1104.

Davig, T. and E. M. Leeper (2011) Monetary-fiscal policy interactions and fiscal stimulus. European Economic Review 55(2), 211-227.

De Castro, F. and P. Hernández de Cos (2008) The economic effects of fiscal policy: The case of Spain. Journal of Macroeconomics 30(3), 1005-1028.

Draghi, M. (2014) Unemployment in the euro area, Speech by Mario Draghi, President of the ECB. In: Annual Central Bank Symposium in Jackson Hole, Vol. 22, Federal Reserve Bank of Kansas City.

Drautzburg, T. and H. Uhlig (2015) Fiscal stimulus and distortionary taxation. Review of Economic Dynamics 18(4), 894-920.

Dupor, B. and R. Li (2015) The expected inflation channel of government spending in the postwar US. European Economic Review 74, 36-56.

Eggertsson, G. B. (2011) What fiscal policy is effective at zero interest rates? In: D. Acemoglu and M. Woodford (eds.), NBER Macroeconomics Annual 2010, Vol. 25, Chicago: University of Chicago Press, pp. 59-112.

Ellahie, A. and G. Ricco (2017) Government purchases reloaded: Informational insufficiency and heterogeneity in fiscal VARs. Journal of Monetary Economics 90, 13-27.

Erceg, C. and J. Lindé (2014) Is there a fiscal free lunch in a liquidity trap? Journal of the European Economic Association 12(1), 73-107.

Fatás, A. and I. Mihov (2001) The Effects of Fiscal Policy on Consumption and Employment: Theory and Evidence, CEPR Discussion Papers 2760.

Fernández-Villaverde, J., G. Gordon, P. Guerrón-Quintana and J. F. Rubio-Ramirez (2015) Nonlinear adventures at the zero lower bound. Journal of Economic Dynamics and Control 57, 182-204.

Fernández-Villaverde, J., P. Guerrón-Quintana and J. F. Rubio-Ramírez (2014) Supply-side policies and the zero lower bound. IMF Economic Review 62(2), 248-260.

Fischer, S. (2016) Longer-Term Challenges for the US Economy, Speech at "A Conversation with Stanley Fischer", sponsored by the Council on Foreign Relations, New York, New York, November 21, 2016.

Forni, M. and L. Gambetti (2010) Fiscal Foresight and the Effects of Goverment Spending, CEPR Discussion Papers 7840.

Guerrieri, L. and M. Iacoviello (2015) Occbin: A toolkit for solving dynamic models with occasionally binding constraints easily. Journal of Monetary Economics 70, 22-38.

Hall, R. E. (2009) By How Much Does GDP Rise if the Government Buys More Output? NBER Working Paper 15496.

Hebous, S. (2011) The effects of discretionary fiscal policy on macroeconomic aggregates: A reappraisal. Journal of Economic Surveys 25(4), 674-707.

Hills, T. S. and T. Nakata (2018) Fiscal multipliers at the zero lower bound: The role of policy inertia. Journal of Money, Credit and Banking 50(1), 155-172.

Ilzetzki, E., E. G. Mendoza and C. A. Végh (2013) How big (small?) are fiscal multipliers?. Journal of Monetary Economics 60(2), 239-254.

IMF (2017) Seeking Sustainable Growth: Short-term Recovery, Long-Term Challenges, World Economic Outlook, International Monetary Fund.

Ji, Y. and W. Xiao (2016) Government spending multipliers and the zero lower bound. Journal of Macroeconomics 48, 87-100.

Jordà, Ò. (2005) Estimation and inference of impulse responses by local projections. American Economic Review 95(1), 161-182.

Kiley, M. T. (2016) Policy paradoxes in the New Keynesian model. Review of Economic Dynamics $21,1-15$. 
Klein, M. and R. Winkler (2018) The Government Spending Multiplier at the Zero Lower Bound: International Evidence from Historical Data, Working Papers 2018001, University of Antwerp.

Leeper, E. M., N. Traum and T. B. Walker (2017) Clearing up the fiscal multiplier morass. American Economic Review 107(8), 2409-2454.

Leeper, E. M., T. B. Walker and S.-C. S. Yang (2010) Government investment and fiscal stimulus. Journal of Monetary Economics 57(8), 1000-1012.

Leeper, E. M., T. B. Walker and S.-C. S. Yang (2013) Fiscal foresight and information flows. Econometrica 81(3), 1115-1145.

Mertens, K. R. S. M. and M. O. Ravn (2014) Fiscal policy in an expectations-driven liquidity trap. The Review of Economic Studies 81(4), 1637-1667.

Miyamoto, W., T. L. Nguyen and D. Sergeyev (2018) Government spending multipliers under the zero lower bound: Evidence from Japan. American Economic Journal: Macroeconomics 10(3), 247-277.

Morita, H. (2015) Japanese Fiscal Policy Under the Zero Lower Bound of Nominal Interest Rates: Time-Varying Parameters Vector Autoregression, IER Discussion Paper 627, Institute of Economic Research Hitotsubashi University.

Mountford, A. and H. Uhlig (2009) What are the effects of fiscal policy shocks?. Journal of Applied Econometrics 24(6), 960-992.

Perotti, R. (2008) In search of the transmission mechanism of fiscal policy. In: D. Acemoglu, K. Rogoff and M. Woodford (eds.), NBER Macroeconomics Annual, Vol. 22, University of Chicago Press, pp. 169-226.

Qazizada, W. and E. Stockhammer (2015) Government spending multipliers in contraction and expansion. International Review of Applied Economics 29(2), 238-258.

Ramey, V. A. (2011) Identifying government spending shocks: It's all in the timing. The Quarterly Journal of Economics 126(1), 1-50.

Ramey, V. A. and S. Zubairy (2018) Government spending multipliers in good times and in bad: Evidence from US historical data. Journal of Political Economy 126(2), 850-901.

Roulleau-Padeloup, J. (2018) The government spending multiplier in a (mis) managed liquidity trap. Journal of Money, Credit and Banking 50(2-3), 293-315.

Stock, J. H. and M. W. Watson (2001) Vector autoregressions. The Journal of Economic Perspectives 15(4), 101-115.

Uhlig, H. (2010) Some fiscal calculus. American Economic Review 100(2), 30-34.

Woodford, M. (2011) Simple analytics of the government expenditure multiplier. American Economic Journal: Macroeconomics 3(1), 1-35.

Yang, S.-C. S. (2005) Quantifying tax effects under policy foresight. Journal of Monetary Economics 52(8), 1557-1568.

Yang, S.-C. S. (2007) Tentative evidence of tax foresight. Economics Letters 96(1), 30-37.

\section{APPENDIX A: IMPULSE RESPONSES BASED ON LOCAL PROJECTIONS}

As discussed in the main text, the Local Projection (LP) method can generate impulse response functions that are more robust to projection bias than VAR-based impulse response functions, especially at longer horizons (see Jordà, 2005). To verify that our main results do not suffer from this bias, we apply the LP method to obtain the cumulative government consumption and investment multipliers, both with and without a binding effective 

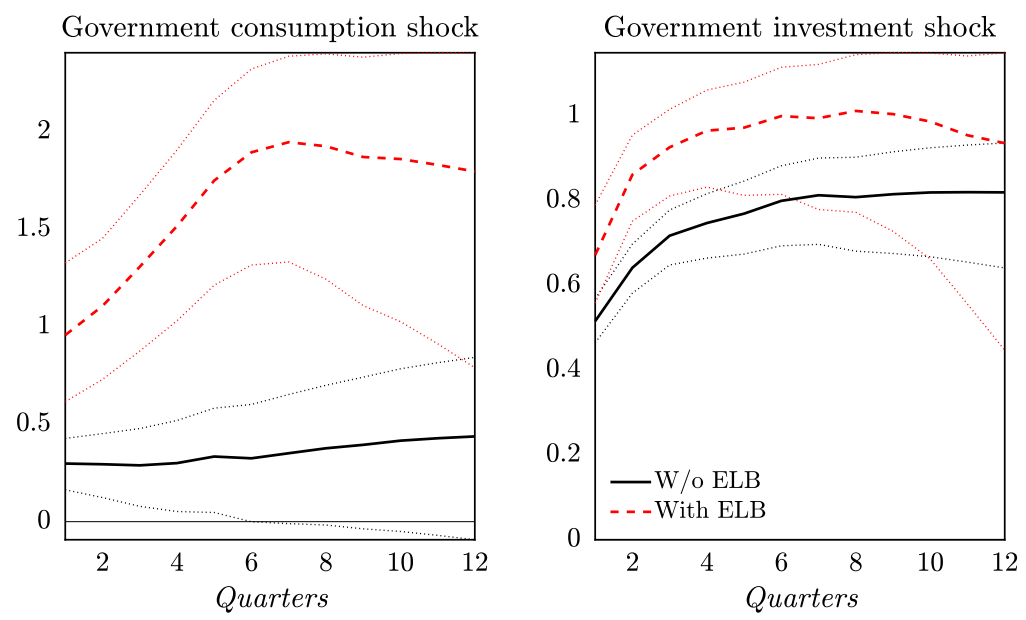

Notes: The shocks are scaled to be $1 \%$ of GDP. The upper (lower) bounds are calculated by adding (subtracting) 1.645 times the standard errors. Units are in percentages.

FigURE A1. Cumulative fiscal multipliers based on the LP approach.

lower bound (ELB), and compare the results to those generated by the panel VAR model from the main text.

In particular, for each forecast horizon $h=0,1,2, \ldots, H$, with $H$ the total impulse response horizon, the following panel regression is estimated:

$$
y_{n, t+h}=\sum_{k=1}^{K} B_{h+1, k} Y_{n, t-k}+e_{n, t+h},
$$

and the impulse response at $h$ is computed as

$$
I_{h}\left(t, h, \eta_{n}\right)=B_{h, 1} \eta_{n},
$$

where $\eta_{n}$ are the government expenditure shocks obtained from the panel VAR model, and $t$ and $n$ are time and country indices, respectively. ${ }^{24}$ Note that this method yields different coefficient matrices, $B_{h, k}$, for each different forecast horizon $h$, and thereby does not compound the potential estimation bias at longer horizons. We set $H=12$ and keep $K$ the same as in our VAR model, that is, $K=5$ for the government consumption model and $K=6$ for the government investment model.

The LP-based impulse response functions are shown in Figure A1 and convey a similar message as our main results from the panel VAR model: the government spending multiplier is positive, and more so when the ELB is binding than when it is not. This result is most pronounced for the government consumption shock, which generates a multiplier that exceeds unity when the ELB binds, and lies below unity when it does not bind. The difference between the government investment multipliers across the two regimes is less prevalent, yet significant and again in line with our main results. 